\title{
Going all the way: \\ The implications of life history and phenotype on reproductive success of the common triplefin Forsterygion lapillum
}

\section{Benjamin Frank Moginie}

\author{
A thesis \\ submitted to Victoria University of Wellington \\ in partial fulfilment of the requirement \\ for the degree of \\ Master of Science in Marine Biology
}

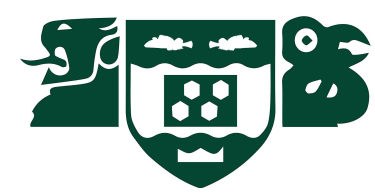

Victoria UNIVERSITY OF WELLINGTON

Te Whare Wānanga o te Ūpoko o te Ika a Māui 


\section{Abstract}

Identifying sources of variation in individual reproductive success is crucial to our understanding of population dynamics and evolutionary ecology. In many systems, the determinants of success are not well known. Where species have parental care, for example, determinants of success can be particularly challenging to partition between parents and offspring. In this thesis I investigate drivers and consequences of variable life histories, for a small reef fish that exhibits male parental care the common triplefin Forsterygion lapillum). I examined the influence of individual life history, phenotype and behaviour on (1) the performance of recently settled juveniles, and (2) the reproductive success adult males.

I made field-based observations of adult males during the breeding season, measured their phenotypic traits (body size and condition) and used their otoliths to reconstruct life history characteristics (hatch dates and mean growth rates). My life history trait reconstructions suggested two alternate pathways to 'success' for adult males. Successful males hatched earlier and therefore had a developmental 'head start' over less successful males (i.e., males with eggs $>$ male territory holders without eggs $>$ floaters). Alternatively, males can apparently achieve success by growing faster: for males born in the same month, those with eggs grew faster than those with territories and no eggs, and both groups grew faster than floaters. These results suggest that accelerated growth rate may mediate the effects of a later hatch date, and that both hatch dates and growth rates influence the success of adult males, likely through proximate effects on individual phenotypes.

Identifying sources of variation in individual reproductive success is crucial to our understanding of population dynamics and evolutionary ecology. In many systems, the determinants of success are not well known. Where species have parental care, for example, determinants of success can be particularly challenging to partition between parents and offspring. Male parental care is common among fishes, where resources such as high quality territories and mates often may be limiting. In such systems, individual success of offspring may result from distinct life history pathways that are influenced by both parental effects (e.g., timing of reproduction) and by the offspring themselves (e.g., 'personalities'). These pathways, in turn, can induce phenotypic variation and affect success later in life. The drivers and consequences of variable life histories are not well understood in the context of reproductive success.

In this thesis I investigate drivers and consequences of variable life histories, for a small reef fish that exhibits male parental care (the common triplefin Forstery- 
gion lapillum). I examined the influence of individual life history, phenotype and behaviour on (1) the performance of recently settled juveniles, and (2) the reproductive success adult males. I made field-based observations of adult males during the breeding season, measured their phenotypic traits (body size and condition) and used their otoliths to reconstruct life history characteristics (hatch dates and mean growth rates). Some males showed no evidence of territorial defence and were defined as 'floaters'; others defended territories, and a subset of these also had nests with eggs present. Adult male body size was significantly higher for males that defended breeding territories, and body condition was significantly higher for the males that had eggs (i.e., had successfully courted females). My otolith-based reconstructions of life history traits suggested two alternate pathways to 'success' for adult males. Successful males hatched earlier and therefore had a developmental 'head start' over less successful males (i.e., males with eggs $>$ male territory holders without eggs $>$ floaters). Alternatively, males can apparently achieve success by growing faster: for males born in the same month, those with eggs grew faster than those with territories and no eggs, and both groups grew faster than floaters. These results suggest that accelerated growth rate may mediate the effects of a later hatch date, and that both hatch dates and growth rates influence the success of adult males, likely through proximate effects on individual phenotypes. 
I evaluated the effects of variable life history in a complimentary lab-based study. Specifically, I manipulated the developmental environments (feeding regime and temperature) for young fish and evaluated the direct effects on life history traits and phenotypes. Then, I conducted an assay to quantify the indirect effects of developmental environment, life history traits, and phenotypes on aggression and performance of young fish. These developmental environments did not have a clear, overall effect on juvenile phenotype or performance (i.e. behavioural aggression and the ability to dominate a resource). Instead, individuals (irrespective of developmental environment) that grew faster and/or longer pelagic larval durations had increased odds of dominating a limited resource. I attributed the non-significant direct effect of developmental environment to within-treatment mortality and variation among individuals in terms of their realised access to food (i.e., dominance hierarchies were apparent in rearing chambers, suggesting a non-uniform access to food). Fish that were more likely to dominate a resource were also more aggressive (i.e., more likely to engage in chasing behaviours). Fish that were larger and more aggressive established territories that were deemed to be of higher 'quality' (inferred from percent cover of cobble resources). Overall, this study suggests a complex interplay between social systems, phenotype and life history. Developmental environments may influence phenotypes, although behavioural differences among individuals may moderate that effect, contributing to additional variation in phenotypes and life history traits which, in turn, shape the success of individuals.

Collectively, my thesis emphasises the consequences of life history variability on success at multiple life stages. These results may be relevant to other species that exhibit male parental care or undergo intense competition for space during early life stages. In addition, my results highlight interactions between life history, phenotype and behaviour that can have important implications for population dynamics and evolutionary ecology. 


\section{Acknowledgments}

Firstly, I'd like to thank my supervisor Jeff Shima. Your generosity has been overwhelming. You gave me ample opportunities to work, both here at VUCEL and over in Melbourne (employing me four times!) and funded my Master's degree, not to mention assisting with all the qualifications. Your guidance, support and advice have been instrumental over the last 4 years, I cannot thank you enough.

To the Shima lab, thank you all for your support throughout my Master's degree. Becky and Phoebe, thank you so much for diving with me in winter to collect samples, feeding my fish when I was away, and helping me with basically everything else. Snout, cheers for all your advice throughout my thesis - both with experimental design and with all things technical - and turning me into the semi-respectable diver I am today. Paul, thanks for your advice at the start of my thesis, and Conor, thanks for your help at the end!

Lab technicians, you were fantastic. Cheers John for sorting everything I needed for my experimental set ups, even at short notice and thanks Dan for helping to collect samples.

To the whole crew down at VUCEL, thank you guys for making my Master's degree unforgettable. You guys motivated me to work hard and were always around for a laugh, a beer, and when I least expected it, a pie in the face. I couldn't imagine a better place to work.

Alice, I can't thank you enough for your endearing love and support which has kept me focussed and motivated over the last 2 years. Thank you Mum and Dad for all your support and kindness throughout this whole journey, particularly over the last few months. I wouldn't be here without it.

Lastly, I'd like to give a big thanks to Victoria University and the Royal Society of New Zealand for funding the scholarships that enabled me to complete this thesis.

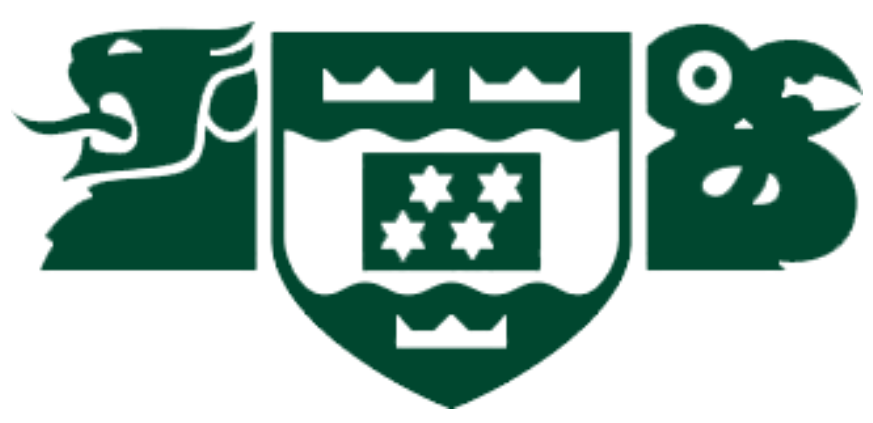




\section{Table of Contents}

Table of Contents

List of Figures

$\mathbf{v}$

List of Tables $\quad x$

1 General Introduction 1

1.0.1 Systems with male parental care . . . . . . . . . . . 2

1.0.2 Determinants of success . . . . . . . . . . . . . . 3

1.0 .3 Study species . . . . . . . . . . . . . . . . . . 9

1.0 .4 Thesis structure . . . . . . . . . . . . . . . . . . 9

2 Early or burly? Hatch date and growth rate as drivers of success in male common triplefin (F. lapillum)

2.1 Introduction . . . . . . . . . . . . . . . . . . . . 11

2.2 Methods .......................... 13

2.2.1 Study species and system . . . . . . . . . . . . . . . 13

2.2.2 Sample collection . . . . . . . . . . . . . . . . . 14

2.2.3 Estimating predictors of reproductive success . . . . . . . . 14

2.2.4 Statistical analyses . . . . . . . . . . . . . . . . . . . . 15

2.3 Results . . . . . . . . . . . . . . . . . . . 16

2.3.1 Effects of body size and condition . . . . . . . . . . 16

2.3.2 Effect of hatch date . . . . . . . . . . . . . . . . . . 16

2.3 .3 Growth history . . . . . . . . . . . . . . . . 16

2.4 Discussion . . . . . . . . . . . . . . . . . . 21

2.4 .1 Phenotype .......................... 21

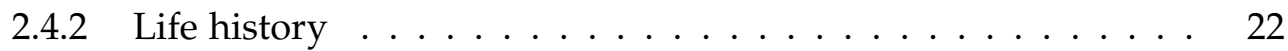

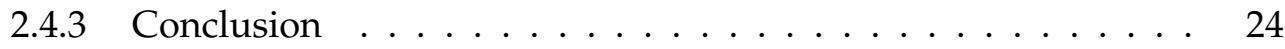

3 Developmental environment and life history: determining the success of a juvenile reef fish 25

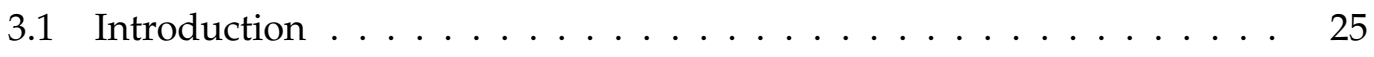

3.2 Methods . . . . . . . . . . . . . . . . . . 28

3.2.1 Study species and system . . . . . . . . . . . . . . . 28

3.2.2 Sampling sites and procedure . . . . . . . . . . . . 28

3.2.3 Developmental environment growth manipulation . . . . . . 28

3.2.4 Estimating pelagic larval duration and lifetime growth rates . 29

3.2 .5 Assessing competitive ability . . . . . . . . . . . . . . 30 
3.2.6 Assessing aggression, territory size and territory quality . . . 31

3.2.7 Statisitcial analyses . . . . . . . . . . . . . . . 32

3.3 Results . . . . . . . . . . . . . . . . . . 34

3.3.1 Developmental environment on juvenile body size and condition 34

3.3.2 Reconstructing life history traits . . . . . . . . . . . 34

3.3.3 Predictors of resource occupation . . . . . . . . . . . 35

3.3.4 Effect of resource occupation on aggression $\ldots \ldots \ldots 35$

3.3.5 Predictors of juvenile territory size and quality . . . . . . 38

3.4 Discussion . . . . . . . . . . . . . . . . . . . 40

3.4.1 Treatment effects on growth and size . . . . . . . . . 40

3.4 .2 Predicting competitive ability . . . . . . . . . . . . 41

3.4.3 Competitive ability and individual aggression . . . . . . . . 43

3.4.4 Effects of phenotype and aggression on territory distriubtion . 44

3.4 .5 Conclusion . . . . . . . . . . . . . . . 45

4 General discussion $\quad 46$

4.1 Overview ........................... 46

4.2 Determining success . . . . . . . . . . . . . . . 46

4.2 .1 Adult males . . . . . . . . . . . . . . . . . . . 46

4.2 .2 Recently settled juveniles . . . . . . . . . . . . . . . 48

4.3 Limitations . . . . . . . . . . . . . . . . . . . . . . . . . 50

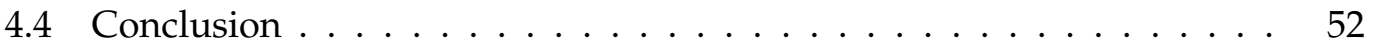

Bibliography

$\begin{array}{ll}\text { Appendices } & 67\end{array}$ 


\section{List of Figures}

Chapter 1

1.1 Background: Male in black breeding colour emerging from a nest. Foreground: Female (or male out of breeding colour). Photo Credit: Becky Focht. . . . . . . . . . . . . . . . . . . . .

1.2 F. lapillum eggs $(\mathrm{n}=\sim 1,400)$ on the underside of a cobble (guarded by an adult male) in Kau Bay, Wellington, New Zealand. Photo Credit: Phoebe Caie. . . . . . . . . . . . . . . . . . . . . . . . . . . . . . 10

\section{Chapter 2}

2.1 (a) A male common triplefin in nuptial colours being measured for standard length, (b) a sagittal otolith under 50x magnification, before being ground to expose daily rings . . . . . . . . . . .

2.2 Comparison of mean standard length and body condition (Fulton's $\mathrm{K})$ of males of different reproductive status; males not guarding territories (Floaters), males guaridng territories without eggs, and males guarding territories with eggs. Letters indicate groupings based on Tukey pair-wise comparisons ( $\alpha$ : 0.05). Response axes are offset from 0 for graphical presentation. Error bars represent $95 \%$ confidence intervals. . . . . . . . . . . . . . . . . . . .

2.3 Proportion of males with different reproductive status that hatched during each month from October 2013 to June 2014 . . . . . . . . . . .

2.4 Relationship betwen growth rate and hatch date among males of different reproductive status; males without territories (Floater), males with territories but no eggs, and males with territories with eggs present. Response axis is offset from 0 for graphical presentation. . . .

2.5 Comparison of mean growth rates among males of different reproductive status that hatched during the same months (March and April 2014). Asterisk incates significant difference in growth rate among groups in that month. Response axis offset from 0 for graphical presentation. Error bars represent $95 \%$ confidence intervals. . . . . . . . .

\section{Chapter 3}

3.1 A juvenile common triplefin among cobble substrate in Kau bay, Wellington, New Zealand. Photo credit: Ben Moginie. . . . . . . . . . 27 
3.2 Layout of growth manipulation expermient, 8 bins containing 10 recently settled common triplefin in either 'high growth' or 'low growth' conditions. Photo credit: Ben Moginie . . . . . . . . . . . . .

3.3 Plastic bin contaning 5 juvenile F. lapillum and $400 \mathrm{~cm}^{2}$ of unevenly distributed cobble substrate . . . . . . . . . . . . . . . . .

3.4 Comparison of mean standard length and body condition for juveniles reared in 'high' and 'low' growth treatments Response axes are offset from 0 for graphical presentation. Error bars represent $95 \%$ confidence intervals. . . . . . . . . . . . . . . . . .

3.5 Mean number of aggressive actions for fish of each occupation rank (1, 2, 3 and 4) when all ranks are present (i), after the sequential removal of the first occupant (ii) and second occupant (iii). Letters (a, b) represent groupings based on Tukey test $(\alpha: 0.05)$. Error bars reperesent $95 \%$ confidence intervals. . . . . . . . . . . . . . .

3.6 Liner relationships between territory size and (A) aggression, (B) standard length and $(\mathrm{C})$ body condition, and between territory quality and (D) aggression, (E) standard length and (F) body condition. Full circles $(\bullet)$ represent juveniles in mesocosm A and open circles (o) represent juveniles from mesocosm B. Slopes of trend lines represent the relationship between the dependant and independant variable after blocking for the effects of bins. Some axes are offset from 0 for graphical purposes. . . . . . . . . . . . . . . . . .

3.7 A simple conceptual model of the trade-off of the effects of body size on survival and compeititon for settling common triplefin. . . . . . . .

\section{Chapter 4}

1 A sagittal otolith (200x magnification) extracted from a juvenile F. lapillum after being hand-ground to expose daily growth increments. The red transect line is drawn from the 'hatch check' (A) to the 'settlement check' (B) across the postrostral axis, as defined by Shima and Swearer (2009). Photo credit: Ben Moginie . . . . . . . . . . . . . . .

2 Frequency bar chart of size classess of juveniels exposed to the 'low' growth treatment. Classes are split into $1.9 \mathrm{~mm}$ groups based on standard length. Grey bars represent fish pre-treatment and white bars represent fish post-treatment ............. 


\section{List of Tables}

Chapter 2

Chapter 3

3.1 Comparison of models derived from 'global models' containing either standard length or average growth rate, in addition to the PLD, growth treatment and body condition using AICc. $\Delta \mathrm{i}$ represents the difference in AICc values between model i and the best fitted model, $\omega$ represents the Akaike weight. Bold text signifies the best fitted model from each of the global models. . . . . . . . . . . . . . . . . . . . . . . . 36

3.2 Linear relationships between the predictor variables 'Average aggresion', 'Standard length' and 'Body condition', and repsonse variables 'Territory size' and 'Territory quality' after blocking for the effect of 'mesocosm'. Bold $\mathrm{p}$ values represent significance at an $\alpha$ of $0.05 \ldots$. . 


\section{CHAPTER 1}

\section{General Introduction}

Variation in individual reproductive success forms the basis of evolutionary theory (Williams, 1992). Identifying the determinants of reproductive success has been, and continues to be, one of the greatest challenges in ecology and evolutionary biology. Predictors of success have been identified among a diverse array of taxa (CluttonBrock, 1988; Bercovitch, 1991), however for many systems and species, the predictors of success are still poorly understood. For example, in systems with male parental care, predictors of male reproductive success often relate to both territoriality and female choice (Gross and Sargent, 1985), but favourable male traits are often highly variable and are yet to be identified in many species. Typically, male success varies with individual phenotype (e.g., body size, condition or behaviour [Anderson, 1988]) and the presence or degree of variation in phenotypic traits is often shaped by developmental history (e.g., evident from a range of measurable life history traits including growth rates and hatch/birth dates [Clutton-Brock, 1988]). Yet few studies of systems with male care account for variation in developmental history and its associated effects on individual phenotypes and reproductive success.

Furthermore, for species with complex life cycles, determinants of survival and reproduction may change with ontogeny (Werner and Gilliam, 1984). Consequently, such organisms should be expected to evolve life-stage-specific adaptations to maximise survival throughout development, and through to sexual maturity (Williams, 1992). For many reef fish, distinct ontogenetic change occurs as pelagic larvae settle to the benthos. In heterogeneous benthic environments (e.g., coral and rocky reefs), fine-scale differences in environmental conditions may influence growth and phenotypes among neighbouring individuals (e.g., Nielsen, 1992; Baltz et al., 1998). However, the consequences of variable growth and condition during development, and particularly, the carry-over effects on future success of older life stages, is still poorly known. This thesis addresses the drivers and consequences of variation in a set of phenotypic, behavioural and life history traits that may predict success of both recently settled juveniles and adult males of a reef fish. I address these questions using a species (the common triplefin, Forsterygion lapillum), where male parental care is a prominent feature. 


\subsubsection{Systems with male parental care}

A diversity of breeding systems have evolved among animals, all of which vary in their level of parental investment. At one end of the spectrum broadcast spawners release gametes directly into the surrounding environment and provide no postfertilization care to their developing young. The offspring of these species are typically poorly provisioned (e.g., in terms of yolk sac) and often suffer extremely high mortality rates, but because they can be produced in such great numbers, it becomes probable that some will survive until reproductive maturity (Vance, 1973). This reproductive strategy is common among sedentary marine invertebrates (e.g., corals [Levitan, 2005] and echinoderms [Schmidt-Roach et al., 2012]), and many marine fishes (e.g., cod [Hutchings et al., 1999], goatfish, wrasse and parrotfish [Habrun and Sancho, 2012]). At the other end of the investment-spectrum, offspring may be nurtured by their parents for extended periods of time. Large terrestrial mammals such as elephants, tigers and humans produce few young, into which they invest enormous amounts of energy. Females that adopt this strategy are often viviparous, with long gestation times, and provide ongoing post-natal care that can last months, years or, in the case of our own species, decades (Kiltie, 1982). Although only few offspring are produced, increased parental investment increases the likelihood that offspring will reach maturity and contribute to the next generation (Clutton-Brock, 1991). Between these extreme ends of the spectrum, a myriad of reproductive investment strategies have evolved to maximise reproductive success for both males and females. Some systems are well studied and the determinants of success have been thoroughly investigated (Clutton-Brock, 1988). However, many systems are still developing a solid theoretical framework to explain their existence and the relative success of individuals engaging in the apparent strategy. An example of a system, for which we know comparatively little, is one featuring male parental care.

Overall, male parental care is far rarer than female parental care and has evolved independently in many different taxa, from birds, to insect and lizards (Clutton-Brock, 1991). Between taxa, males vary in their level of parental investment. In numerous bird and mammal species for example, males mainly provide supplementary offspring care to the female's care (Woodroffe and Vincent, 1994; Cockburn, 2006), though in some insects, males provide sole care for the young (e.g., the assassin bug and the giant water bug [Smith, 1980]). Among fishes, however, solitary male parental care is particularly common (Blumer, 1979).

Gross and Sargent (1985) suggest the evolution of male care in fishes is driven by the 
reduced costs of future reproductive success for male parents compared to female parents. They argue that if parental care demands energy, the guarding parent could be limited in growth of body size (or condition). As body size would not greatly affect male gamete production but would likely affect female gamete production (by limiting the number of eggs she can bear or energy she can invest into each egg [Blumer, 1979]), males gain the same benefits of parental care as females (i.e., increased offspring survival) but suffer fewer reproductive costs. This theory implies that, in systems with male parental care, there should not necessarily be selection for males with larger body sizes. Yet in many species body size is an important determinant of male reproductive success (e.g., Côte and Hunte, 1989; Schuett, 1997; McElligott et al., 2001). Gross and Sargent (1985) suggest selection for larger body sizes in male fish could be driven by the evolution of territoriality. Territoriality is suggested as a strategy that can reduce the cost of parental care in males (Gross and Sargent, 1985) and has been recognised as a prerequisite to the evolution of male parental care in many species (Ah-King et al., 2005). Thus, in systems with male parental care, 'winners' (in terms of reproductive fitness) are the males that successfully secure the best territories, and attract females.

\subsubsection{Determinants of success}

\section{Territoriality}

Territoriality has evolved across the animal kingdom, presumably as a mechanism for individuals to increase their fitness by securing access to limited resources (López-Sepulcre and Kokko, 2005). The nature of the 'resource' varies among taxa, but frequently includes limited food (Ostfeld, 1990), refuge from predators (Stamps, 1983) or potential mates (Thompson, 1986). Commonly, in fishes with male parental care, multiple females may deposit eggs in a particular location (i.e., a 'nest') within a male's territory those eggs are then externally fertilised by the male (Gross and Sargent, 1985). Thus, for males, the limited resource is often suitable nesting sites. If the most successful males simply secure better nesting sites, then determinants of success for males with parental care will include traits that affect competitive ability. In most species, larger body size increases competitive ability or social status, facilitating access to a greater quantity of resources (Brown and Maurer, 1986). In many territorial fishes larger body size often determines competitive outcomes for preferred nesting sites (e.g., Jarvi, 1990; Schuett, 1997; McElligott et al., 2001), and this trait is commonly considered to be key determinant of success in systems with 
territoriality and male parental care. In addition to the competitive advantage, increased body size may reduce chances of losing a secured territory, consequently reducing the chance of offspring mortality caused by conspecific predators (Bisazza et al., 1989). Similarly, increased energy reserves (i.e., body condition) could increase effort spent on aggression (Johnson, 2008), enhancing competitive ability to compete for (or defend) limited resources (Booth and Beretta, 2004), such as preferred nesting sites. Body condition may be particularly relevant for males of many fish species that experience long breeding seasons, during which males tend to sacrifice feeding opportunities and decrease in body condition (and thus potential energy to defend territories). Phenotypic characteristics related to body size and condition are often influenced by life history traits such as timing of hatch or growth during development (e.g, Skoglund et al., 2011) but these relationships are not well studied in the context of male reproductive success.

Investigations that evaluate the potential effects of 'timing of hatch' on future territory acquisition are rare. However, one recent study on a fish with male parental care, Fagundes et al. (2015) found that hatch dates predicted territoriality in male peacock blennies, Salaria pavo. Their study suggests earlier hatching males are likely to be larger and experience greater reproductive success by defending territories. Males that hatched later tended to be smaller in size and were more likely to adopt a 'sneaker' strategy (i.e., foregoing territorial defence entirely, and attempting contribute sperm during female oviposition in a territorial male's nest). Timing of parental hatching may also determine territoriality between similar sized individuals if it also corresponds to an early arrival and settlement to the benthos (i.e., such 'priority effects' have been well-studied for reef fish). Johnsson et al. (1999) and Harwood et al. (2003) both found prior residency predicted the outcome of competitive interactions for a preferred nesting site, despite differences in male size. However, fish may be able to mediate effects of 'hatch date' by developing at different rates. If males secure territories based on their timing of arrival, then another way to arrive early (independent of hatch date) may be to develop faster (i.e., spent less time in the larval life stage). If possible, this could represent an 'alternate pathway' to reproductive success for a male, as it could increase the likelihood of acquisition of preferred nesting sites. Because shorter larval durations for marine reef fish are often correlated with faster larval growth (i.e., one way to shorten development is to grow more quickly; [Shima and Findlay, 2002]), faster growth may also be an important predictor of territorial acquisition and future reproductive success.

The effects of growth rate on territoriality may extend beyond simply reducing de- 
velopment time. Somatic growth rate is defined as the change in body size over time. Therefore, individuals that continue to grow faster should attain a competitive advantage from a larger body size relative to slower growing individuals. Many studies have evaluated growth rate during development, and these typically highlight a strong influence of environmental conditions (e.g., temperature, food availability or turbulence) on somatic growth (Booth and Beretta, 2004; Pauly, 1980; Bergenius et al., 2005). In the marine environment, conditions can vary wildly through time (e.g., across seasons, particularly in temperate and polar zones) and space (e.g., embayments vs. open coast environments), with consequences for individual phenotypes (Shima and Swearer, 2009). In addition, growing evidence suggests environmental conditions over small spatial scales (e.g., microhabitats within coral or rocky reefs) can be an important source of variation in growth among individuals. For example, Baltz et al. (1998) found microhabitat variables such as temperature, salinity and prey diversity explained variation in growth and size patterns in the spotted sea trout (Cynoscion nebulosus), and Nielsen (1992) reported variability in food availability between microhabitats and influenced growth rates among neighbouring coho salmon. Even the physical characteristics of microhabitats (e.g., branching corals) may constrain the growth and shape of fish inhabitants (Munday, 2001; Wehrberger and Herler, 2014). In many cases, marine fishes settle onto heterogeneous benthic environments as they transition from larvae to juveniles, and consequently, they may experience variable growth. Yet the effects of variable post-settlement growth on juvenile phenotype and territory acquisition in species with male parental care are still poorly known.

Phenotypic and life history traits may affect the outcomes of competitive interactions by influencing behavioural attributes such as aggression. Engaging in aggressive interactions is energetically costly (Ros et al., 2006) and often the 'winners' of conflicts are able to sustain aggressive behaviour for longer periods than their competitor (i.e., game theory 'the war of attrition' [Smith, 1979]). Larger individuals are found to be more aggressive in many taxa (e.g., ants [Nowbahari et al., 1999], lizards [Tokarz, 1985] and fish [Schuett, 1997]). Body size may, therefore, act as a signal of competitive ability, and discourage smaller competitors from engaging in aggressive interactions, leaving larger individuals to dominate limited resources (Smith, 1979). Aggression may also vary with previous social experiences (Fuxjager et al., 2010), genetics (Van Oers et al., 2005), or in response to acquiring a valuable resource (Enquist and Leimar, 1987). Despite aggressive behaviour being well documented in territorial animals, the drivers behind individual variation in aggressive behaviour 
are not well understood in many systems.

\section{Female choice}

In addition to territoriality, male reproductive success is often constrained by access to gravid females. Therefore, determinants of success for males also include traits that influence female mate choice (Trivers, 1972). Females, like males, aim to maximise the number of offspring that they contribute to future generations. In systems with sole male care, offspring survival is heavily dependent on the quality of parental care provided by the father. In this case, female choice should be determined by the quality of care that males are able to provide to the offspring (Andersson, 1994; Maller and Thornhill, 1998). In some instances, offspring survival increases with male-associated traits, such as nest size or nest quality. Here, female choice reflects the competitive ability of the males to gain the best nesting sites. For example, Bisazza et al. (1989) documented female freshwater gobies (Padogobius martensi), favoured males with larger nest sites, that were often larger in body size, but otherwise selected males randomly with respect to body size. In these cases females are indirectly selecting for male traits that enhance competitive ability, thus reducing the determinants of success for males of that species. This may also occur if traits that increase male competitive ability also increase the quality of care he is able to provide. For example, Lindström and Hellström (1993) found larger male sand gobies Pomatoschistus minutus spent more time fanning (aerating) eggs than did smaller males. However, in most species the determinants of territoriality differ from those of female mate choice, meaning that selection should reflect an optimisation between traits that affect competitive ability and female mate choice. To date, most studies have assessed these (potentially opposing) drivers of fitness in isolation; few studies investigate how both constraints affect males success, particularly in wild populations.

Studies of female choice frequently suggest that females use male body condition (i.e., available energy reserves) as a key indicator of male quality. Increased energy reserves may prevent fathers from resorting to filial cannibalism (as guarding males tend to decrease in condition throughout a breeding season [Gomagano and Kohda, 2008]) or reduce the time a male spends away from a nest site to forage (leaving eggs exposed to predation [Côte and Hunte, 1989]). Females may be able to assess the condition of males through the display of 'honest' signals. Honest signals are inadvertent displays of individual condition and, in the context of male care, may be used by females to assess the ability of a potential male to care for a clutch of eggs (Amorim et al., 2013). For example, in species such as the bicolour 
damsel-fish Stegastes partitus, the rate of courtship display is an 'honest' indicator of male energetic reserves and correlates to egg survival in male nests (Knapp and Kovach, 1991). Similarly, the red nuptial colouration of male three-spine sticklebacks (Gasterosteus aculeatus) reflects male condition and predicts increased egg survival (Candolin, 1999, 2000).

In many cases, the traits favoured by females may contradict those associated with male competitive ability. For example, Forsgren (1997) found females preferred "good fathers" (i.e., males with higher hatching success) over dominant males. However, dominant males still received matings by limiting female access to the "good fathers". In a similar scenario, females may prefer to mate with males that have already received clutches of eggs (e.g., Ridley and Rechten, 1981; Marconato and Bisazza, 1986; Forsgren et al., 1996, but see Andrén and Kvarnemo, 2014). In one species, the striped darter Etheostoma virgatum, Porter et al. (2002) suggest the males have evolved 'egg-like' spots to mimic the possession of eggs under their care, in order to attract matings. Indeed, they found males with a greater number of eggs spots were favoured by visiting gravid females. A possible explanation for this phenomenon has been attributed to filial cannibalism (Forsgren et al., 1996). A study by Lindstrom and Sargent (1997) suggests males guarding larger clutches of eggs are less likely to cannibalise their entire clutch, compared to males guarding smaller clutches. Therefore, a female may increase the chances of survival of her offspring by depositing the eggs in the nest of a male that is already guarding eggs. Additionally, females may further increase their reproductive success by laying eggs in nests of multiple different males, reducing the risk of losing all their eggs if filial cannibalism was to occur.

The role of male life history characteristics on female choice is not well documented, although (as described above) some studies do indicate the timing of arrival may influence male success (Dickerson et al., 2005). Earlier arriving males may reach maturity faster, allowing them to mate earlier in the breeding season. This may be an advantage if it enables males to access greater per capita egg production by females that may occur at the start of the breeding season (Mensink, 2014). Additionally, for species with a limited breeding season, earlier maturing males may also be able to breed a greater number of times over the breeding season. Conversely, in some species, later arriving males may experience greater reproductive success. For example, Candolin and Voigt (2003) found predation risk for males was elevated at the start of the breeding season so later arriving males may benefit from increased survival; later arriving males in this study also tended to be larger in size, and thus 


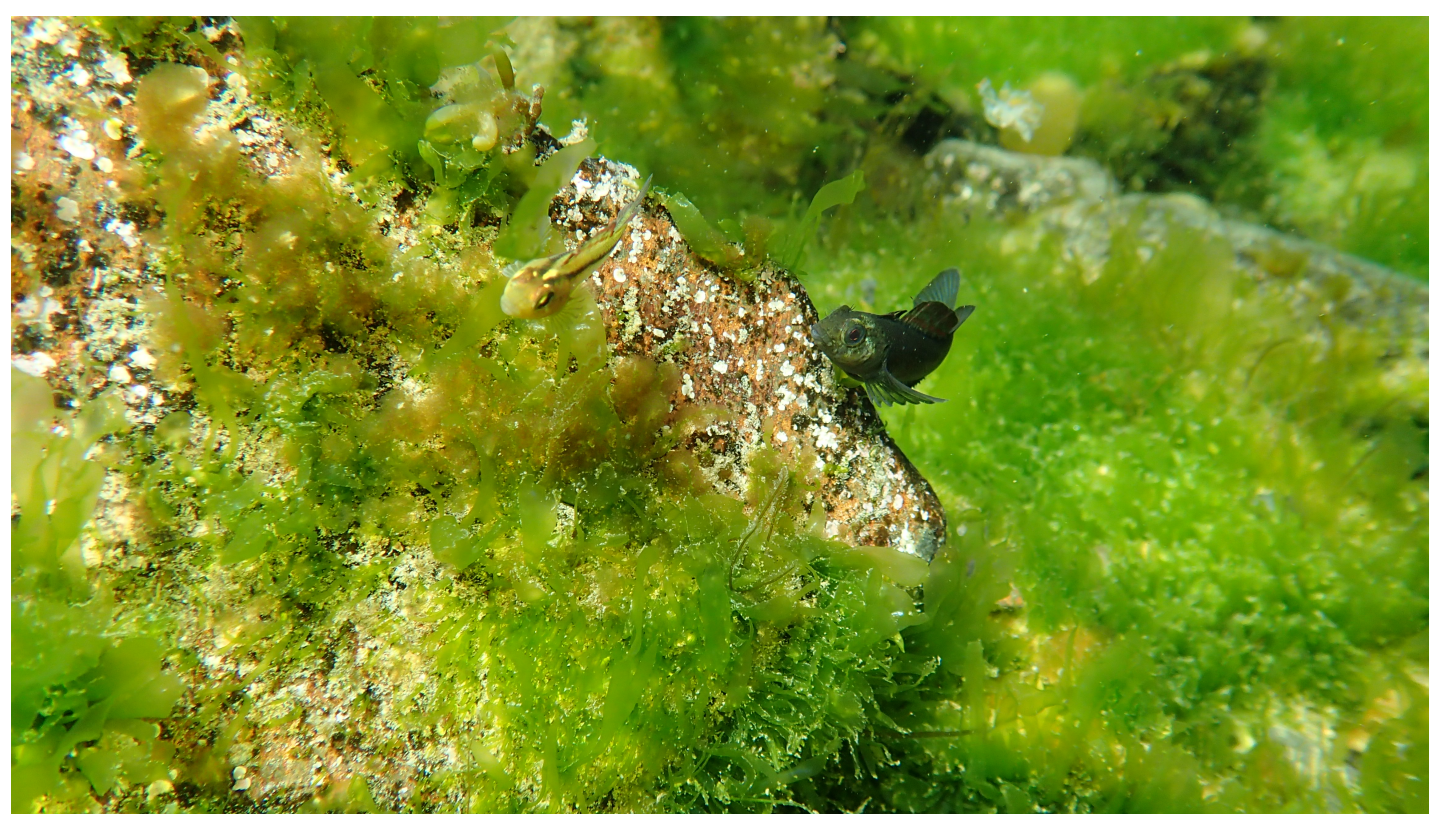

Figure 1.1: Background: Male in black breeding colour emerging from a nest. Foreground: Female (or male out of breeding colour). Photo Credit: Becky Focht.

able to usurp the territories that were established by earlier arriving males.

Hatch dates could also influence other phenotypic traits favoured by females. Individuals that hatch at different times of the year may experience very different developmental conditions, with consequences for their growth, phenotype and behaviour (Nicieza and Metcalfe, 1999). Similarly, growth rates may affect the development of phenotypic or behavioural traits used to attract females (see above for further examples). Surprisingly, the timing of male hatch or growth rates have rarely been investigated as a determinant of female choice.

Determining success of males in species with male paternal care requires the investigation of factors that determine both territoriality and female choice. The literature suggests important correlations between life history, phenotype and behaviour, yet few studies investigate these relationships in the context of male success. Life history traits arising from different developmental histories (e.g., hatch dates, growth rate) may have under-appreciated consequences for our understanding of population dynamics and evolutionary ecology. 


\subsubsection{Study species}

My thesis aims to address the determinants of reproductive success for a small reef fish, the common triplefin (Forsteygion lapillum Hardy, 1989), which serves as a model system for a species with male paternal care. The common triplefin is widely distributed around the coast of New Zealand (Francis, 2001). F. lapillum are blennioid fish of the family Tripterygiidae, the most diverse family of coastal fishes in New Zealand (Francis, 2001). Adults average are abundant in shallow rocky reefs of New Zealand (Willis, 2001), primarily occupying cobble habitats (Feary and Clements, 2006). Males and females share a pale mottled-brown colouration for most of the year. However, when the breeding season commences (August-November for Wellington) mature males tend to adopt a distinctive mating pigmentation; uniform black with a blue stripe lining the anal fin (Fig. 1.1). Throughout the breeding season, adult males defend territories containing nesting sites (usually the sloped underside of a cobble [Francis, 2001]). Gravid females deposit egg masses on a sloped undersurface within a selected male's territory (Feary and Clements, 2006, Fig. 1.2), leaving him to guard and aerate the eggs until they hatch. Males that have successfully courted females may guard 2000 eggs at any given time and may receive multiple clutches of eggs throughout a breeding season (Mensink et al., 2014). Larvae hatch after $\sim 2$ 2-3 weeks (Francis, 2001) and return to a reef after $\sim 52$ days (Shima and Swearer, 2009). Upon reaching the reef, larvae settle among fronds of brown algae and appear to remain there for approximately 2 two weeks before moving to the benthos as juveniles (McDermott and Shima, 2006). Benthic juveniles then remain in small home ranges (Mensink and Shima, 2015) through to adulthood. Adults F. lapillum display strong site fidelity (Shima et al., 2012) - males during the breeding season are particularly site attached, whereas females tend to travel more widely in pursuit of courtship opportunities (Clements, 2003).

\subsubsection{Thesis structure}

In chapter two, I investigate the determinants of reproductive success in adult males of the common triplefin. I randomly sample a population of adult males and categorise them based on their reproductive status (as territory holders with eggs present, territory holders without eggs, or non-territorial 'floater' males). I measure phenotypic traits and reconstruct life history characteristics to evaluate the hypotheses that reproductive status is predicted by (i) size and/or body condition, (ii) timing of hatching, and/or (iii) growth rate during development. In this chapter, I address 


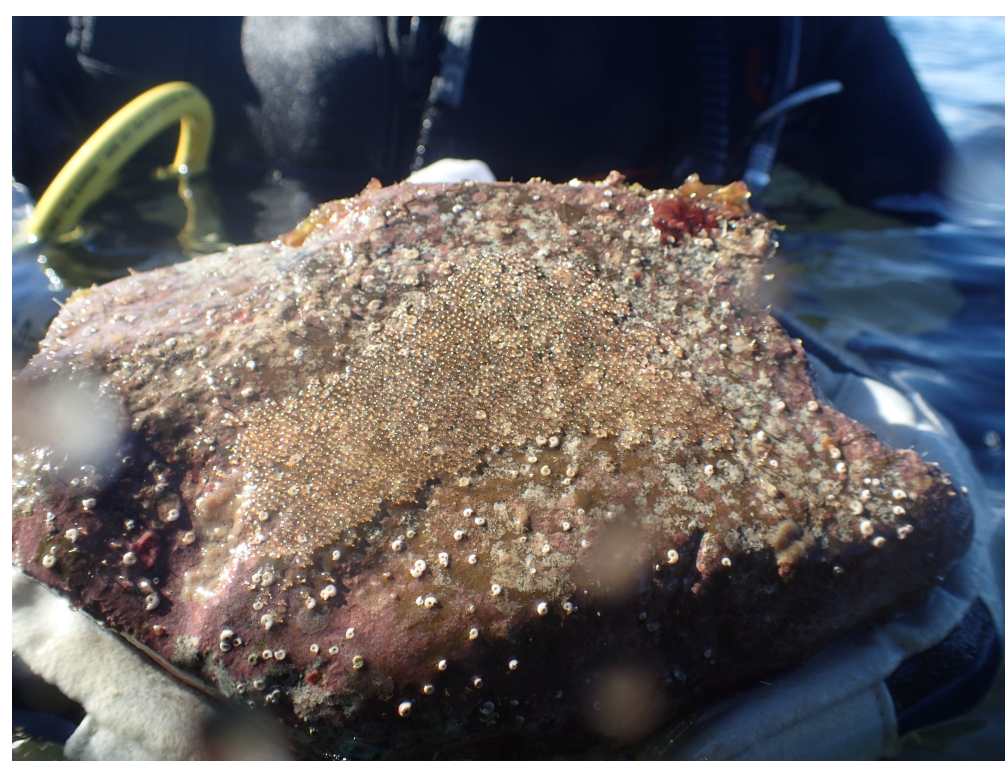

Figure 1.2: F. lapillum eggs $(\mathrm{n}=\sim 1,400)$ on the underside of a cobble (guarded by an adult male) in Kau Bay, Wellington, New Zealand. Photo Credit: Phoebe Caie.

the relationship between life history and phenotype in the context of male success, for systems with male parental care.

In chapter three, I conduct a lab-based study to investigate the patterns of territoriality and habitat occupation by a settling cohort of juveniles. I manipulated the developmental environments (feeding regime and temperature) for young fish and evaluated the direct effects on life history traits and phenotypes. Then, I conducted a set of assays to quantify the indirect effects of developmental environment, life history traits, and phenotypes on aggression and performance of young fish. I tested the hypotheses that (i) developmental environments induce differences in body size, body condition and growth; (ii) combined influences of developmental environments, body size, body condition, pelagic larval duration, and/or growth rates predict 'success' of individuals (as assessed by their ability to acquire limited habitat resource); (iii) 'successful individuals' are more aggressive and, (iv) fish that are aggressive, larger and/or in better condition can acquire territories that are of higher quality.

I have formatted this thesis to facilitate publication of my two data chapters; hence there is some overlap in material presented in the following chapters (e.g., particularly in introductions and discussions). 


\section{CHAPTER 2}

\section{Early or burly? Hatch date and growth rate as drivers of success in male common triplefin $(F$. lapillum)}

\subsection{Introduction}

Variation in individual reproductive success is a cornerstone of evolutionary theory (Williams, 1992). Although much research has evaluated determinants of reproductive success for a wide variety of organisms and systems (Clutton-Brock, 1988; Bercovitch, 1991), these remain poorly known for many species (Clutton-Brock, 1988). Body size, condition, growth, and timing of birth/hatching are identified as important contributors to reproductive success in many different taxa, including plants (Michael A. Farris, 1990; Warwick and Brock, 2003; Winter et al., 2008), reptiles (Ruby, 1984; Madsen et al., 1993; Olsson and Shine, 1996), mammals (Wauters and Dhondt, 1989; Hodge et al., 2008), birds (G. A. Lozano, 1996; Mauck et al., 2004) and fishes (Jacob et al., 2009; Buston and Elith, 2011).

In many animal systems females may choose males in an attempt to maximise their own fitness (Andersson, 1994). Sexual selection theory (Andersson, 1994) suggests females are likely to favour males that express traits indicative of fitness benefits to the female (i.e., traits that could increase number of offspring surviving to reproductive age). Female choice is particularly common in species featuring male parental care, and in these systems male reproductive success may also be determined by quality of care males are able to provide to the offspring (Andersson, 1994; Maller and Thornhill, 1998). The question 'what makes a good male' has been addressed for many species with male parental care. For example, females of the sand goby, (Pomatoschistus minutus) prefer males with higher nest quality (Lehtonen and Lindstrom, 2009). Female Azorean rock-pool blennies (Parablennius parvicornis) prefer males based on expressions of courtship and parental behaviour (Oliveira et al., 2000), and female song sparrow favour males with larger song repertoires (Reid et al., 2004).

For species in which males provide parental care, large body size and/or increased body condition of males is almost always favoured by females (Masello and Quillfeldt, 2003). Large size can be beneficial to male caregivers for a variety of rea- 
sons. For example, males with larger body sizes may possess sufficient energetic reserves enabling them to provide care for longer durations (Côte and Hunte, 1989; Lindström and Hellström, 1993). For pouch-brooding males, larger body size and a larger pouch is associated with improved survival of offspring (Dzyuba et al., 2006). Larger males often rank highly in social dominance hierarchies, which can reduce likelihood of egg predation by conspecifics (Bisazza et al., 1989) and ensure access to better nesting sites (Rowland, 1989; Magnhagen and Kvarnemo, 1989; Perrone, 1978; Candolin and Voigt, 2001). Similarly, increased body condition may provide honest signals to females of a male's increased reproductive output (Chastel et al., 1995), attractiveness to other females (Morales et al., 2003) or prolonged lifespan (Kasumovic et al., 2009).

Body size and condition are often functions of individual birth/hatch date and growth rate. Earlier hatching individuals may have more time to grow larger (in size or weight) before the onset of the mating season compared to later hatching individuals (Lindholm et al., 1994; Cargnelli and Gross, 1996) and faster growers, by definition, increase in size more than slower growers over any given length of time. If increased body size and condition are linked to male success in systems with male parental care, then its probable that variation in hatch date and growth rate also determine male reproductive success. Additionally, the timing of birth or hatch (i.e.,'birth date effects') may extend beyond phenotypes. For example, variation in hatch date may affect timing of maturation (Uller and Olsson, 2010), future reproductive strategy (Fagundes et al., 2015) or vulnerability to predators (Karban, 1982). Similarly, growth rates may also affect male success independently of phenotype, by influencing longevity (reviewed in Metcalfe and Monaghan, 2003) or timing of maturation (Rowe and Thorpe, 1990). Yet, few studies investigate life-history characteristics that may influence male reproductive success in these systems.

Here, I investigate a set of traits that may contribute to male reproductive success in the common triplefin, Forsterygion lapillum. This species has male parental care, and an accessible record of life-history traits associated with developmental history (provided by the growth increments recorded within 'ear stones', or otoliths). I quantify morphological traits and reconstruct life-history traits of adult males that differ in their breeding status. I evaluate the hypotheses that male reproductive status is predicted by (i) body size and/or condition, (ii) timing of hatching, and/or (iii) growth rate during development. 


\subsection{Methods}

\subsubsection{Study species and system}

The common triplefin is a small, temperate fish widely distributed around the New Zealand coast (Francis, 2001). Common triplefin are exposed to a range of environments associated with ontogenetic shifts throughout their lifetime. Typically, eggs are laid on cobble substrate of coastal rocky reefs (Wellenreuther and Clements, 2007a) and hatch as larvae after $\sim 2-3$ weeks (Francis, 2001). After $\sim 52$ days larvae return to a rocky reef (Shima and Swearer, 2009) and settle to- and remain within fronds of brown algae for $\sim 14$ days before moving to the benthos as juveniles (McDermott and Shima 2006) and developing into mature adults. During the spawning season (August - November for study location), sexually mature males assume nuptial pigmentation, changing from a mottled, pale-brown colouration to a more uniformly black colouration with a blue stripe lining their anal fin (Wellenreuther and Clements, 2007a). Common triplefin display resource defence polygamy where mature males defend territories containing potential nesting sites (typically the underside of a cobble [Francis, 2001]) and display vigorous courtship behaviour at passing females (Handford, 1979). Adult females deposit their eggs on a chosen male's nest (Feary and Clements, 2006) leaving him to provide sole parental care that consists of aeration and defence of eggs until hatching. Having successfully courted a female, a male guards $\sim 2000$ eggs on average and may receive multiple clutches of eggs throughout his reproductive lifetime (Mensink et al., 2014).

In this study I defined 2 criteria to identify the 'reproductive status' of adult males made at a single observation time. Firstly, I classified each fish as either 'territorial' or 'non-territorial' based on evidence of site attachment (i.e., returns after displacement (Maher and Lott, 1995), exclusive use (i.e, the sole occupant of the cobble [Petty and Grossman, 2007]) and behaviour patterns consistent with territorial defence (i.e., chases directed at other individuals [(Maher and Lott, 1995)]). Secondly, I subdivided 'territorial' fish based upon the presence or absence of eggs on their nesting site. This method enabled me to categorise males as (i) non-territorial males ('floaters'), (ii) territorial males without eggs or (iii) territorial males with eggs.

Admittedly, this approach provides only a 'snapshot' of the reproductive status of each male, and does not take into account variation in individual reproductive status over time. I sampled at random intervals through time and make an assumption that my sampling effort (detailed below) was sufficient to evaluate a relationship between 
reproductive status and measured traits.

\subsubsection{Sample collection}

I collected adult male F. lapillum from a single site (Kau Bay in Wellington Harbour, $\left.41^{\circ} 17^{\prime} 11.74^{\prime \prime S}, 174^{\circ} 49^{\prime} 43.37^{\prime \prime} \mathrm{E}\right)$ repeatedly over a 4 month period during the 2014 breeding season (Aug- Nov). Specifically, I collected fish with hand nets (aided by the use of SCUBA), along a permanently marked transect. My transect was $60 \mathrm{~m}$ long, running parallel to the shoreline along a $\sim 5 \mathrm{~m}$ depth contour. I collected males haphazardly along this transect over 15 sampling dates from August- November. On each sampling date, I characterised the reproductive status of sampled males as either (i) floaters, (ii) territorial males without nests, or (iii) territorial males with nests. All males collected were identified by their conspicuous mating colouration, however the colouration of F. lapillum may change post-mortem (regardless of reproductive status), so any ambiguous individuals were dissected to identify reproductive organs and confirm sex. Females were excluded from all analyses.

\subsubsection{Estimating predictors of reproductive success}

\section{Phenotypic traits}

I quantified a set of phenotypic and life-history traits for sampled males, and evaluated their ability to predict variation in breeding status. Specifically, I measured the size (standard length) of fish to the nearest millimetre using callipers (Fig. 2.1a), and quantified mass to $0.0001 \mathrm{~g}$ using a microbalance. I calculated a metric of body condition (Fulton's K; Ricker 1975) as:

$$
K=\frac{\text { Wet weight }}{\text { Standard length }}
$$

\section{Life history traits}

I used otoliths to reconstruct individual life histories (dates of hatching and growth rates). Specifically, I extracted sagittal otoliths from each fish and placed them in $15 \%$ mol $\mathrm{H}_{2} \mathrm{O}_{2}$ for 12 hours to remove tissue (Fig. 2.1b). Otoliths were mounted on plastic discs in a clear resin and hand-polished with $9 \mu \mathrm{m}$ diamond lapping films (3M) to expose daily growth increments. I evaluated a single otolith for each fish, and took a series of photos through a light microscope (using a Cannon D3-50) along the postrostral axis. Images were then aligned in a common focal plane to obtain a complete and uninterrupted record of daily increments. I used image analysis 


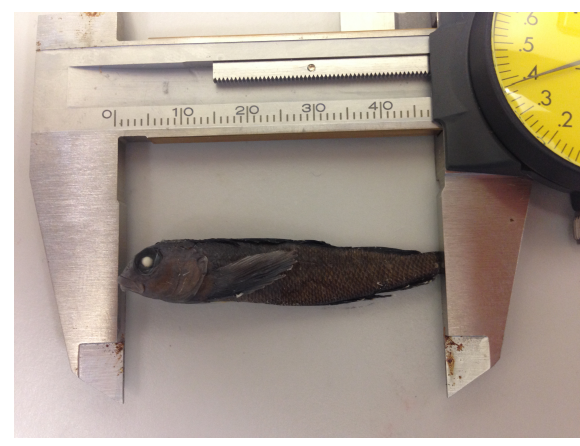

(a)

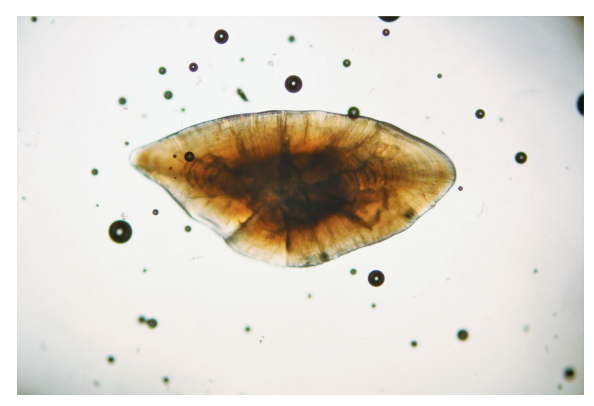

(b)

Figure 2.1: (a) A male common triplefin in nuptial colours being measured for standard length, (b) a sagittal otolith under 50x magnification, before being ground to expose daily rings

software (ImagePro Premier 9.1) to count and measure daily increments. I identified a 'hatch check' as an approximate doubling in increment width near the centre of the otolith (after Shima and Swearer 2009). For each fish, I estimated cumulative 'age' as the number of increments from the hatch check to the otolith edge. To calculate the 'hatch date' I subtracted 'age' from the date the fish was sacrificed. I estimated 'mean growth rate' over the lifetime of the fish as the standard length divided by 'age'. I validated a sample of increment counts against those made by a second observer (J.S. Shima); the two independent counts differed by less than $3 \%$ on average.

\subsubsection{Statistical analyses}

Males were collected randomly over sampling dates and were pooled across sampling dates for all analyses. I used set of ANOVAs to evaluate the hypotheses that males of differing reproductive status (i.e., floaters, territory holders without nests, or territory holders with nests) varied in: (i) size (standard length), (ii) body condition (Fulton's K), and (iii) hatch date. I used ANCOVAs to assess how the relationship between growth and hatch date varied with reproductive status. To investigate differences in growth rate between males of different reproductive status during March and April 2014, I statistically accounted for variation in hatch date between males (using 'Least Square Means', or LS means) and compared the resulting LS-mean growth rates among males of differing reproductive status using paired t-tests. Assumptions of statistical tests were satisfactorily met for all statistical analyses.

All statistical procedures were performed using R Statistical Software V. 3.2.2. (R core Team 2015) 


\subsection{Results}

I sampled 141 adults, and of these, 55 were categorised as 'floater' males and 86 were territorial males. Eggs were present in 47 of the 86 territories and absent in the remaining 39. I was not able to reconstruct life-history traits for all sampled fish due to imperfections in otoliths. I successfully resolved daily otolith increments for the entire postrostral axis for a subset of 51 males (20 floater males, 18 territorial males without eggs and 13 males with eggs present), allowing me to estimate hatch dates, and growth rates for these individuals.

\subsubsection{Effects of body size and condition}

Standard length of sampled males ranged from 33.90 to $53.07 \mathrm{~mm}$, and varied significantly with reproductive status $\left(F_{2,138}: 22.566, \mathrm{P}<0.001\right.$; Fig. $\left.2.2 \mathrm{i}\right)$. For territorial males, standard length did not differ with respect to the presence or absence of a eggs, however both types of territorial males were significantly larger in standard length (on average 9.1\%) than floater males (Fig. 2.2i).

Body condition of sampled males ranged from $8.54 \times 10^{-6}$ to $2.05 \times 10^{-5} \mathrm{~g} / \mathrm{mm}^{-3}$ and also varied significantly with reproductive status $\left(F_{2,138}\right.$ : 9.886, $\mathrm{P}<0.001$; Fig. 2.2ii). Body condition did not differ between floater males and territorial males with no eggs. However, territorial males with eggs present had a condition index $6.1 \%$ higher than the other two groups (Fig. 2.2ii).

\subsubsection{Effect of hatch date}

My reconstructions from otoliths suggest that sampled males hatched over a 9 month period, from the 11-Oct-2013 to the 15-June-2014, with a median hatch date of 9March-2014. Hatch dates differed among males of different reproductive status $\left(F_{2,49}\right.$ : 44.284, $\mathrm{P}<0.001$, Fig. 2.3). Floater males hatched significantly later than both territorial males with eggs (Tukey: $\mathrm{P}<0.001)$ and without eggs $(\mathrm{P}<0.001)$. For territorial males, hatch date was earlier for males with eggs compared to males without eggs (P: 0.009).

\subsubsection{Growth history}

Growth rates for sampled males increased with hatch date irrespective of their reproductive status $\left(F_{1,48}: 262.99\right.$, P: $<0.001$, Fig. 2.4). However, the relationship between growth rate and hatch date varied with male reproductive status (interac- 

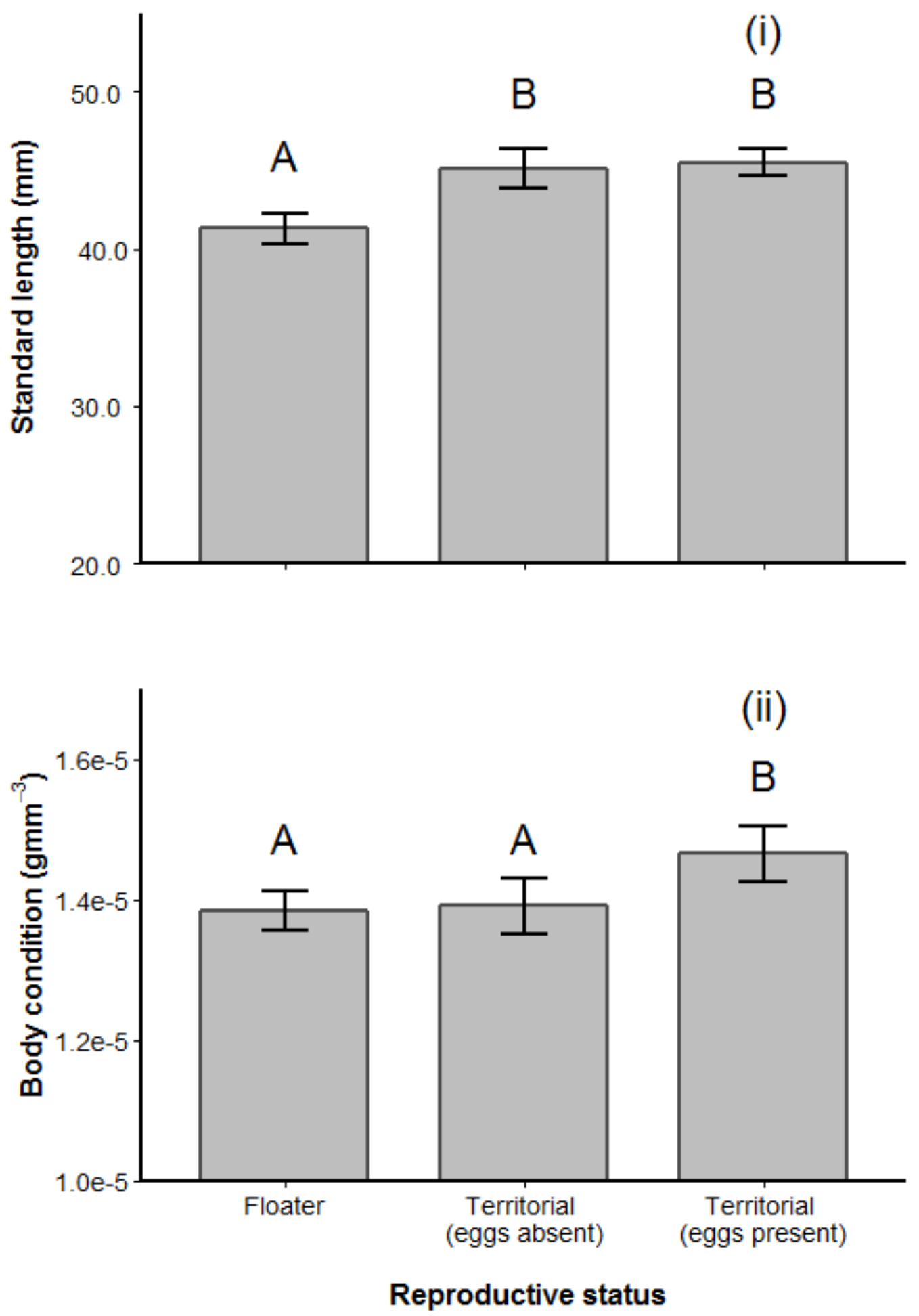

Figure 2.2: Comparison of mean standard length and body condition (Fulton's K) of males of different reproductive status; males not guarding territories (Floaters), males guaridng territories without eggs, and males guarding territories with eggs. Letters indicate groupings based on Tukey pair-wise comparisons ( $\alpha$ : 0.05). Response axes are offset from 0 for graphical presentation. Error bars represent $95 \%$ confidence intervals. 


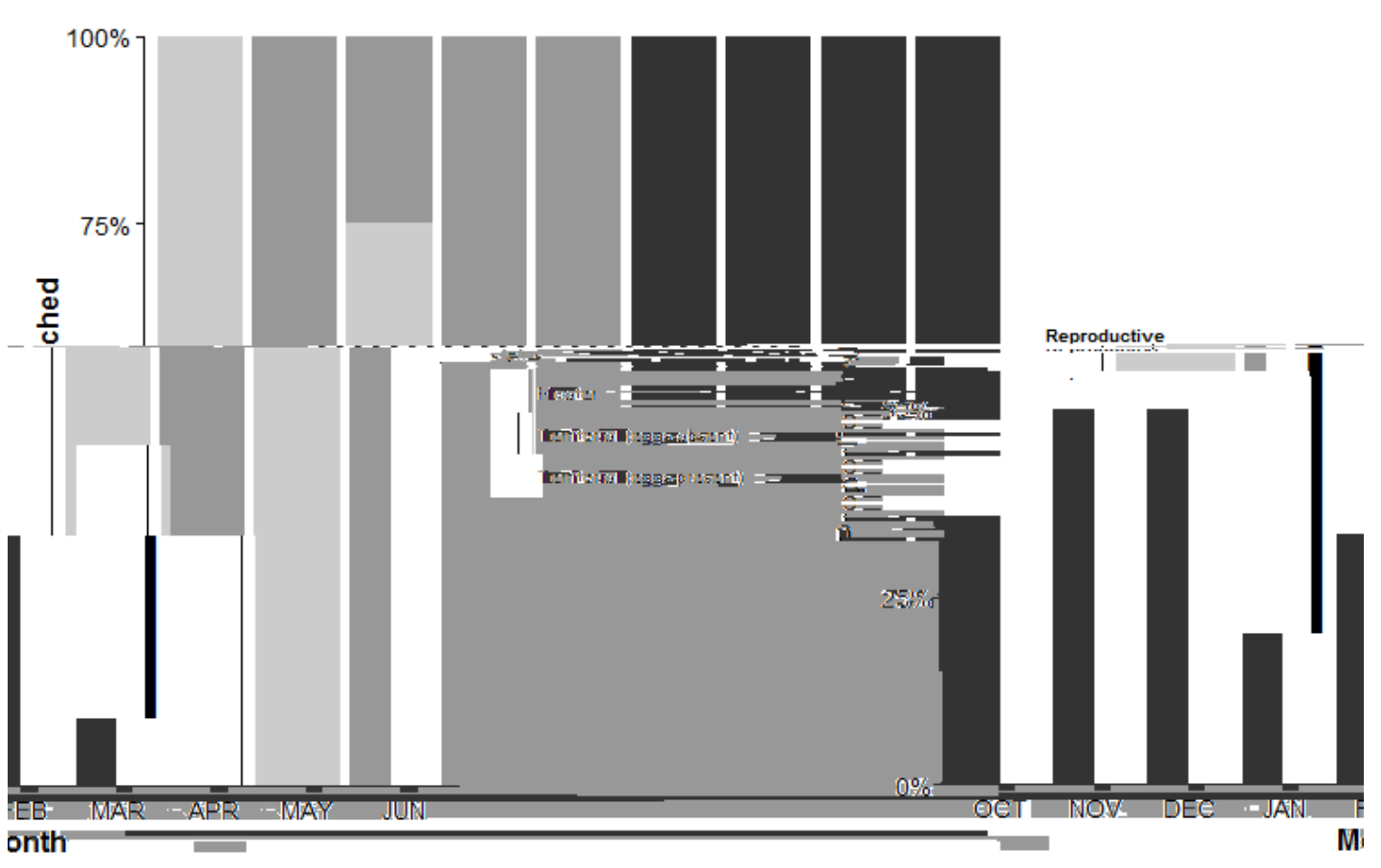

Figure 2.3: Proportion of males with different reproductive status that hatched during each month from October 2013 to June 2014

tion term: $\left.F_{2,46}: 14.087, \mathrm{P}<0.001\right)$. Figure 2.4 illustrates the significant interaction between hatch date and growth is most likely attributable to the steeper relationship between growth rate and hatch date for floaters. Given the minimal overlap in hatch dates between floaters and territorial males I performed two further analyses to investigate the relationship hatch date, growth rate and reproductive status.

Firstly, I conducted a secondary ANCOVA analysis without floaters to evaluate differences in growth between territorial males with egg and without eggs. For the subset of males that were territorial, individuals with eggs had faster growth rates than individuals without eggs regardless of hatch date $\left(F_{1,27}\right.$ : 13.21, P: 0.001). Secondly, I compared adjusted mean growth rates (LS-means) among floaters and territorial males (with and without eggs), for the two months where there was an overlap in hatch date (i.e., in March and April 2014, Fig 2.3). Figure 2.5 illustrates that, for males that hatched in March, adjusted growth rates were higher in territorial males with eggs compared to territorial males without eggs ( $T$ - ratio 36 : 3.476, P: 0.004) and floater males ( $\mathrm{T}-$ ratio $_{36}: 3.199, \mathrm{P}: 0.008$ ). However, adjusted growth rates did not differ between territorial males without eggs and floater males that hatched in either March (T-ratio 36 : 1.133, P: 0.501) or April 2014 (T-ratio $36: 1.133$, P: 0.501). 


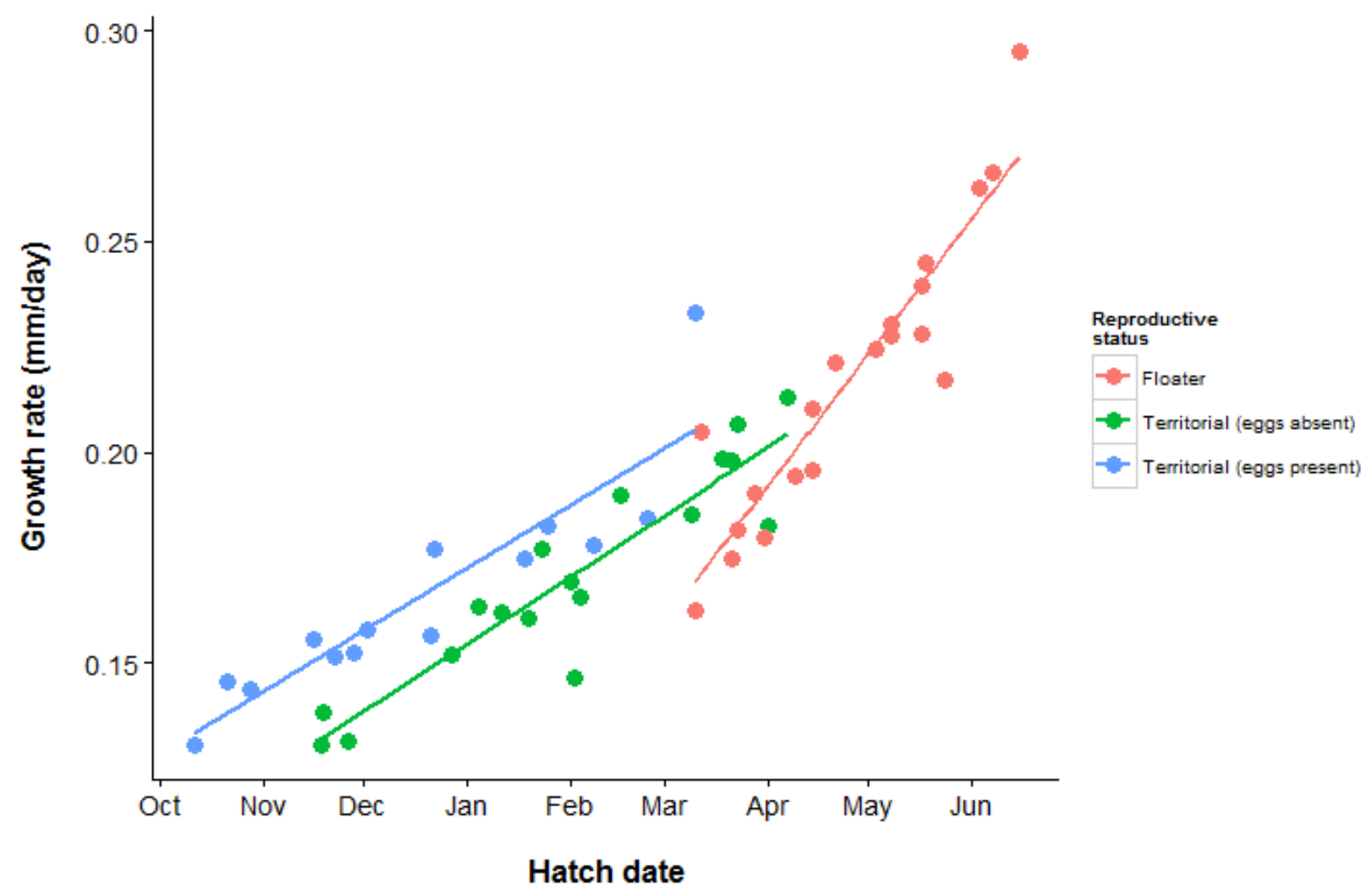

Figure 2.4: Relationship betwen growth rate and hatch date among males of different reproductive status; males without territories (Floater), males with territories but no eggs, and males with territories with eggs present. Response axis is offset from 0 for graphical presentation. 


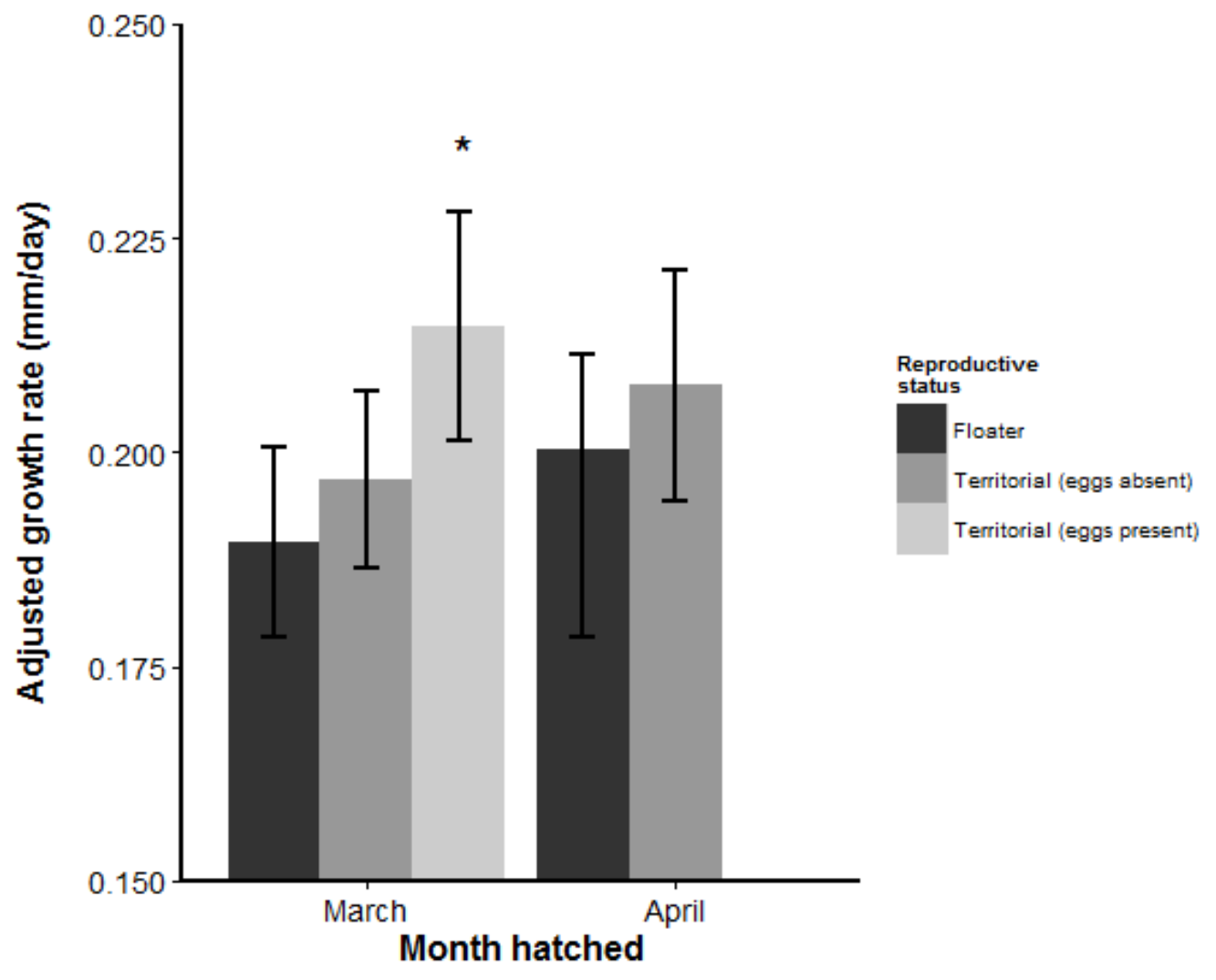

Figure 2.5: Comparison of mean growth rates among males of different reproductive status that hatched during the same months (March and April 2014). Asterisk incates significant difference in growth rate among groups in that month. Response axis offset from 0 for graphical presentation. Error bars represent $95 \%$ confidence intervals. 


\subsection{Discussion}

Identifying determinants of reproductive success has been a focus of investigation for many species and a diversity of mating systems (Clutton-Brock, 1988). In species with male parental care, body size and condition have been identified as important indicators of male fitness, and these traits have been the subject of many studies (e.g., Lindström and Hellström (1993); Uusi-Heikkilä et al. (2011)). Variation in these traits is often closely associated with age (or birth date) and somatic growth rate, yet the latter are seldom considered as underlying drivers of male reproductive success (but see Fagundes et al., 2015). My results suggest that reproductive status of male common triplefin is predicted by differences in size and condition, but also by hatch date, and growth rate. Collectively, these results suggest a population of adult male triplefin is comprised of a mixture of individuals that differ in a range of traits and have corresponding differences in reproductive success.

\subsubsection{Phenotype}

Reproductive status was predicted by differences in body size. Territory holders were larger in body size than floaters. Associations between body size and territoriality are common among fishes (e.g., Magnhagen and Kvarnemo, 1989) and other taxa (O'Neill, 1983; Candolin and Voigt, 2001). Male body size can influence competitive ability (McElligott et al., 2001; Jarvi, 1990) as well as successful acquisition and defence of a territory or nesting site (Cole, 1982).

Differences in body size did not predict the presence or absence of eggs between territorial males (i.e., female male choice) as is suggested other fish species such as the sand goby Pomatoschistus minutus (Lindström and Hellström, 1993) or the closely related mottled triplefin Forsterygion varium (Thompson, 1986). These results also appear to contradict a recent study on the common triplefin by Mensink et al. (2014), which found a significant effect of male body size on the probability of acquiring eggs.

Differences in body condition, however, did predict presence/absence of eggs for territorial males. Females may favour males in better condition for several reasons; elevated condition could indicate greater energy reserves, and thus more energy available for investment in parental care (increasing the quality of care and / or reducing the risk of egg predation by caregiving males [Mackereth et al., 1998; Hanson and Cooke, 2009]). Indeed, Mensink (2014) found F. lapillum egg size was significantly 
correlated to male condition, which may suggest assortative (i.e., size-matched) mating between larger (or better conditioned) females and males.

Conversely, the correlation between increased body condition and presence of eggs may have been driven by another mechanism. Females may lay eggs indiscriminately with respect to male condition, and the apparent absence of eggs associated with males in poorer condition could be the result of filial cannibalism. Males that practice paternal care often decrease in body condition when caring for young (Lindström and Hellström, 1993) and some species may exhibit filial cannibalism (i.e., egg consumption) as a mechanism to maintain body condition during this period (Gomagano and Kohda, 2008; FitzGerald, 1992; Vinyoles et al., 1999). If filial cannibalism was practised by the common triplefin, egg presence may limited to nests of high condition males because males in low condition may be more likely to consume their brood, as opposed to females favouring males in better body condition.

\subsubsection{Life history}

In this study, male F. lapillum were presumed to be sexually mature if they had invested in nuptial colouration. Interestingly, the size-at-maturity for male F. lapillum (of all breeding statuses) in this study appeared smaller than the $50 \mathrm{~mm}$ suggested by Francis, 2001. This could be explained by the reasonably high densities of F. lapillum found in Kau Bay, or the seasonal breeding season which may have accelerated sexual development compared to populations in other geographies, such as the upper North Island (where F. lapillum breed year-round).

Reproductive status of males is also predicted by differences in hatch dates. All sampled males that hatched earlier than March 2014 had acquired territories and all males that hatched earlier than mid-November 2013 successfully obtained eggs (Fig. 2.3). Early hatching dates may have granted the territorial males a longer growing period before the onset breeding season in August 2014, and may have driven the observed differences in body size and condition. Additionally, the wide range in hatch dates ( $~ 9$ months from October 2013 - June 2014) suggests later hatching males may have developed in very different environmental conditions, with possible consequences for individual growth (Brett et al., 1969; Angilletta et al., 2004) and phenotype (Monaghan, 2008; Shima and Swearer, 2009).

Given that males with early hatch dates were more likely to (i) be territorial and (ii) be defending eggs, suggests order of arrival (i.e., 'priority effects') probably influences male reproductive success in the common triplefin. Priority effects have 
been described in many species, for example Geange and Stier (2010) discovered that earlier arriving reef fish were subject to less aggression and were less likely to be displaced from their habitat by competitors, even if they were deemed subordinate. Similarly, subordinate salmon may acquire, and successfully maintain, preferred feeding sites if they arrived prior to a known dominant individual (Harwood et al., 2003), and brown trout fry that had previously obtained a territory were able to successful defend their territory against competitors that were up to $30 \%$ larger in size (Johnsson et al., 1999).

If earlier hatching male triplefin are first to arrive on a rocky reef they too may be more likely to acquire and defend preferable territories compared to their later arriving conspecifics. In addition, earlier arriving males may mature at an earlier date than later arriving males, potentially allowing the earlier hatching males to begin mating earlier in the breeding season, when males typically receive more eggs (Mensink, 2014).

Later hatching males had faster growth rates than earlier hatching males (Fig. 2.4). The significant interaction between growth rate and hatch date was likely due to accelerated growth rates of the floater males (Fig 2.4). Floater males were younger and smaller than territorial males and may not have reached asymptotic size. Alternatively, floaters could have experienced faster growth rates because they hatched and developed in very different environmental conditions than territorial males. However, this would require the colder, rougher sea conditions in which the floaters hatched and developed to promote faster growth than the relatively warm and calm conditions that the territorial males experienced, which seems unlikely given the evidence for the contrary (Friedland et al., 2000; MacKenzie and Kiørboe, 2000; Neuheimer et al., 2011).

The positive relationship between growth rate and hatch date suggest faster growth rates may negatively affect reproductive status (Fig. 2.4). However, after statistically adjusting for hatch date, territorial males with eggs had accelerated growth rates compared to those without eggs. Given the territorial males did not differ in body size, only body condition, this would suggest increased growth rate may increase male body condition after asymptotic body size is reached, subsequently increasing the chance of receiving eggs. Similarly, the comparison of adjusted growth rates for males hatched in March and April 2014 suggested that territorial males with eggs had faster growth rates than both territorial males without eggs and floater males hatched in the same month (Fig.2.5). However, there may fitness consequences 
associated with accelerated growth. For example, in a previous study on common triplefin, Mensink (2014) found faster growing adult males received smaller clutches of eggs than slower growing males. Fast growth during development has also been attributed to reduced reproductive investment (e.g., sexual ornaments) and impaired sexual responsiveness to gravid females (Lee et al., 2012, 2014).

My results indicate the existence of multiple pathways to success for male common triplefin. Reproductive success may be maximised by: (i) hatching early, or (ii) if unable to hatch early, then by faster growth. My study suggests that males born late (after March in this study) may be (iii) adopting an alternative reproductive tactic. Conceivably, these males may become 'sneaker males' (e.g., Fagundes et al., 2015), and parasitise mating events between females and larger males (though admittedly, this is entirely speculative). However, sneaker males are expected to divert energetic resources from somatic growth, and towards reproductive development (i.e., have slower somatic growth rates at smaller sizes [Jennings and Philipp, 1992]). In my study, floater males appeared to have a qualitatively different relationship between growth rates and hatch dates, (Fig.2.5), suggesting that they may be investing disproportionately in growth at the expense of any reproduction. An alternate hypothesis, therefore, is that these late-hatching males forego reproductive attempts in the present season and then attempt to breed in the following season. However, further research would be needed to address this issue.

\subsubsection{Conclusion}

Overall, this study suggests that life history traits (hatch dates and growth rates) could be the ultimate determinants of male reproductive success, particularity in systems with male parental care. Phenotypic variation may be an outcome of these life-history traits, and consequently, they are likely to be the proximate variables upon which females make their choice. Both date of hatching and somatic growth rate predicted territoriality and egg presence in male common triplefin. This distinction is important because it suggests that selective forces on males are likely to favour maternal effects (timing of egg deposition) and environmental (or genetic) factors that may drive differential growth rates. Identifying these life-history determinants has important implications for both population dynamics and evolutionary ecology in systems with male parental care. 


\section{CHAPTER 3}

\section{Developmental environment and life history: determining the success of a juvenile reef fish}

\subsection{Introduction}

In species with complex life cycles, characteristics that determine success may vary with ontogeny. Many organisms have evolved stage-specific adaptations to maximise (i) survival throughout development to sexual maturity, and (ii) future reproductive success after maturity (Werner and Gilliam, 1984). Environmental variability during ontogeny, particularly during early life stages, may have important repercussions on future individual success (Bergenius et al., 2005; Blob et al., 2008). Yet, the consequences of variability in environmental conditions (e.g., temperature and food availability) during early life stages, in relation to individual life histories, are poorly known.

An important ontogenetic shift in life cycle of many reef fishes happens during the transition from the pelagic environment to the benthos (i.e., settlement). Mortality rates are often high for settling individuals, as many benthic environments (particularly reefs) can harbour high densities of predators (Perez and Munch, 2010). A wealth of theoretical and empirical research suggests that settling fish undergo strong selective mortality on body size (Hawn et al., 2005; Meekan et al., 2006; Perez and Munch, 2010; the 'bigger is better' hypothesis', Bailey, 1989) and developmental history (i.e., the 'growth - mortality hypothesis' Anderson, 1988; Meekan and Fortier, 1996).

Variability in growth rates among individuals often arises from environmental heterogeneity (Monaghan, 2008). Oceans may vary wildly in temperature, turbidity or food availability, both temporally (Friedland et al., 2000; MacKenzie and Kiørboe, 2000; Neuheimer et al., 2011) and spatially (Houde, 1989; Shima and Swearer, 2009), facilitating variable growth rates in developing individuals. However, environmental heterogeneity may also influence growth rates on a much finer spatial scale, particularly in complex habitats like coral or rocky reef systems (Munday, 2001; Wehrberger and Herler, 2014). Here, unequal distribution of refuges, conspecifics, food resources and temperature may contribute to variation in individual growth rates and phenotypes (Connell and Jones, 1991; Nielsen, 1992; Baltz et al., 1998). Often, many larvae will settle simultaneously (i.e., as a cohort) onto a heterogeneous benthic environ- 
ment. Consequently individuals within a cohort may settle among different habitats and experience corresponding differences in growth rates as they develop as juveniles (e.g., Tupper and Boutilier, 1995). However, the consequences of pro-longed exposure to optimal and sub-optimal growth conditions on juvenile performance are still poorly understood.

Juveniles of many species obtain territories as refuges or for future reproduction (Ah-King et al., 2005). In this context, a 'winner' is the individual within a cohort that secures the best territory. The competitive outcomes of territorial fishes are often predicted by phenotypic traits (e.g., body size and condition [Perrone, 1978; Magnhagen and Kvarnemo, 1989; Rowland, 1989; Booth and Beretta, 2004]) and behavioural characteristics (e.g., aggression [Cutts et al., 1999]). The size and quality of particular phenotypes (e.g. body size or condition) are expected to indicate individual fighting ability (Smith, 1979). Aggressive displays are energetically costly (Ros et al., 2006) and individuals with increased body condition (i.e., available energy reserves) may be able to increase frequency or intensity of aggressive displays toward territorial neighbours (Bertram and Rook, 2012). However, aggression is often highly context-dependen $t$ (i.e., individual aggression may change depending on conspecific density, dominance status or relative size of neighbouring individuals [Mumby and Wabnitz, 2002]). Yet, few studies investigate whether aggression is a behavioural response to individual context (e.g., an individual's territory quality) or whether aggression predicts individual dominance or success.

In addition to behavioural and phenotypic traits, individual life history characteristics (e.g., growth rate or pelagic larval duration) may play an important role in determining the relative quality of larvae (Shima and Swearer, 2009), and may have carry-over effects into the juvenile life stage (Smith and Shima, 2011). Pelagic larval duration ('PLD') is a measure of the time a larva spends in the pelagic zone, before transitioning to another environment as a juvenile. Shorter PLDs are typically associated with fast growth (Shima and Findlay, 2002) and may increase the odds of an individual obtaining a limited resource as a juvenile, if they transition to the juvenile environment faster than their competitors (i.e., priority effects [Geange and Stier, 2010]). However, the effect of variation in PLD (or growth rate) on the performance of juveniles that settle simultaneously is not well understood.

Growth rates during development likely affect competitive ability through proximate effects on body size; as body size varies as a function of growth rate. Thus, faster growers may have a competitive advantage over slower growers. However, acceler- 


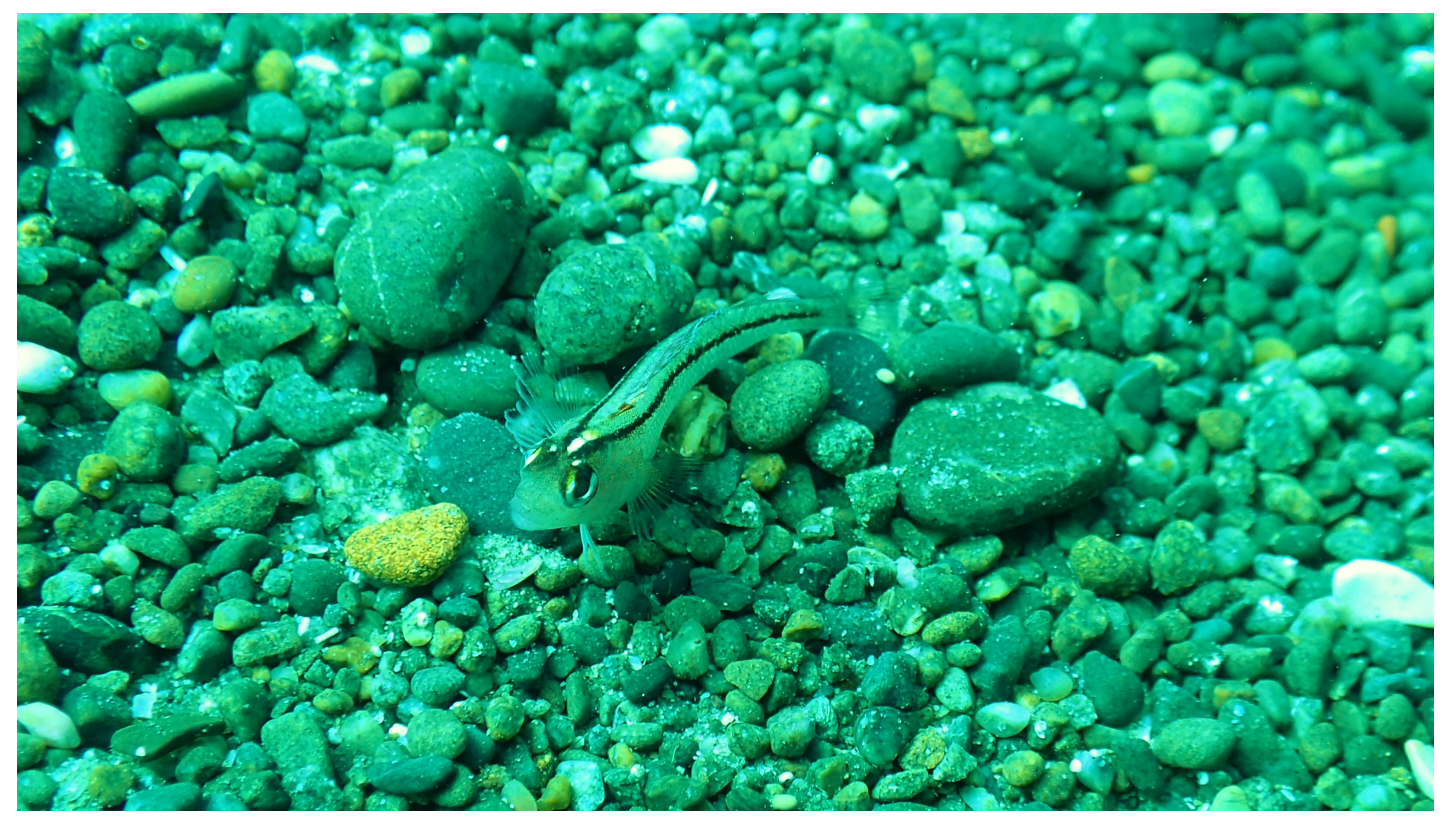

Figure 3.1: A juvenile common triplefin among cobble substrate in Kau bay, Wellington, New Zealand. Photo credit: Ben Moginie.

ated growth may come with costs, such as decreased swimming speed (Álvarez and Metcalfe, 2007) which may reduce competitive ability or future survival (Johnsson and Bohlin, 2006). For one species of rocky reef fish, the common triplefin (Forsterygion lapillum), territories offer refuge and are a prerequisite for breeding success of adult males (Francis, 2001). Common triplefin are known to settle differentially onto rocky reefs with 'patchy' habitat availability (Morton and Shima, 2013, Fig. 3.1). In these environments food resources and temperatures may be spatially heterogeneous, particularly in shallow waters, where high densities of adult common triplefins are frequently observed (Wellenreuther et al., 2007; Mensink, 2014).

Here, I rear fish in different developmental environments and test the hypotheses that (i) developmental environment induces differences in body size and body condition; (ii) combined influences of developmental environments, body size, body condition, pelagic larval duration, and/or growth rates predict 'success' of individuals (as assessed by their ability to acquire limited habitat resource); (iii) 'successful individuals' are more aggressive; and, (iv) fish that are aggressive, larger and/or in better condition can acquire territories that are of higher quality. 


\subsection{Methods}

\subsubsection{Study species and system}

Refer to section 2.2.1

\subsubsection{Sampling sites and procedure}

I collected recently settled common triplefin from three neighbouring sites within Wellington Harbour: Kau Bay $\left(41^{\circ} 17^{\prime} 11.74^{\prime \prime}\right.$, $\left.174^{\circ} 49^{\prime} 43.37^{\prime \prime} \mathrm{E}\right)$, Shelly Bay

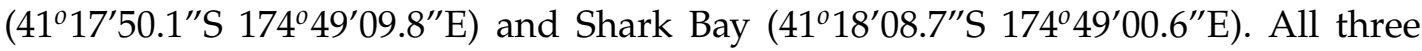
sites have a cobble benthos and a fringing algal community ( $\sim 10 \mathrm{~m}$ offshore). I deployed 14 artificial substrates ('SMURFs', sensu Ammann, 2004; detailed in Shima and Swearer, 2009) at each site to collect recently settled common triplefin. Collectors were deployed on two dates ( $26^{\text {th }}$ of Feb 2015 and $10^{\text {th }}$ of March 2015, ) and recovered by divers after 7 days. Fish were transferred to buckets filled with seawater and transported back to Victoria University's Coastal Ecology Laboratory (VUCEL).

\subsubsection{Developmental environment growth manipulation}

I conducted a manipulative experiment to investigate the effects of variability in 'developmental environment' on individual phenotypes and the ability of juveniles to dominate limited available habitats, in relation to their individual life histories.

Collected fish were photographed individually (using a Cannon TG-03 and a scale bar) and then randomly assigned to either (1) a "low growth treatment" or (2) a "high growth treatment". Fish in the low growth treatment were placed in 60L plastic bins $(\mathrm{n}=4)$ of seawater (with a starting density of $10 \mathrm{fish} / \mathrm{bin}$ ), maintained at $18^{\circ} \mathrm{C}$ and fed ad libitum on a diet of blended frozen mussels (Perna canalicula and Mytilus edulis) at 3-day intervals (Fig. 3.2). Fish in the high growth treatment were reared under similar conditions ( $n=4$ plastic bins), with the exception that they were maintained at $20^{\circ} \mathrm{C}$ (the thermal preference [Khan and Herbert, 2012]) and fed ad libitum on a daily schedule. Each plastic bin was equipped with an aerator, a layer of small cobble stones and had $20 \%$ of the seawater replaced on a 3-day cycle. I maintained fish in these growth regimes for 35 days and then photographed each fish at the end of this study (using a Cannon TG-03 and a scale bar). I used ImageJ (Ver.1.48) to calibrate photos and measure standard lengths of each fish within treatment bins, before and after the feeding regime. I calculated body condition as 'Fulton's K' (wet weight / 


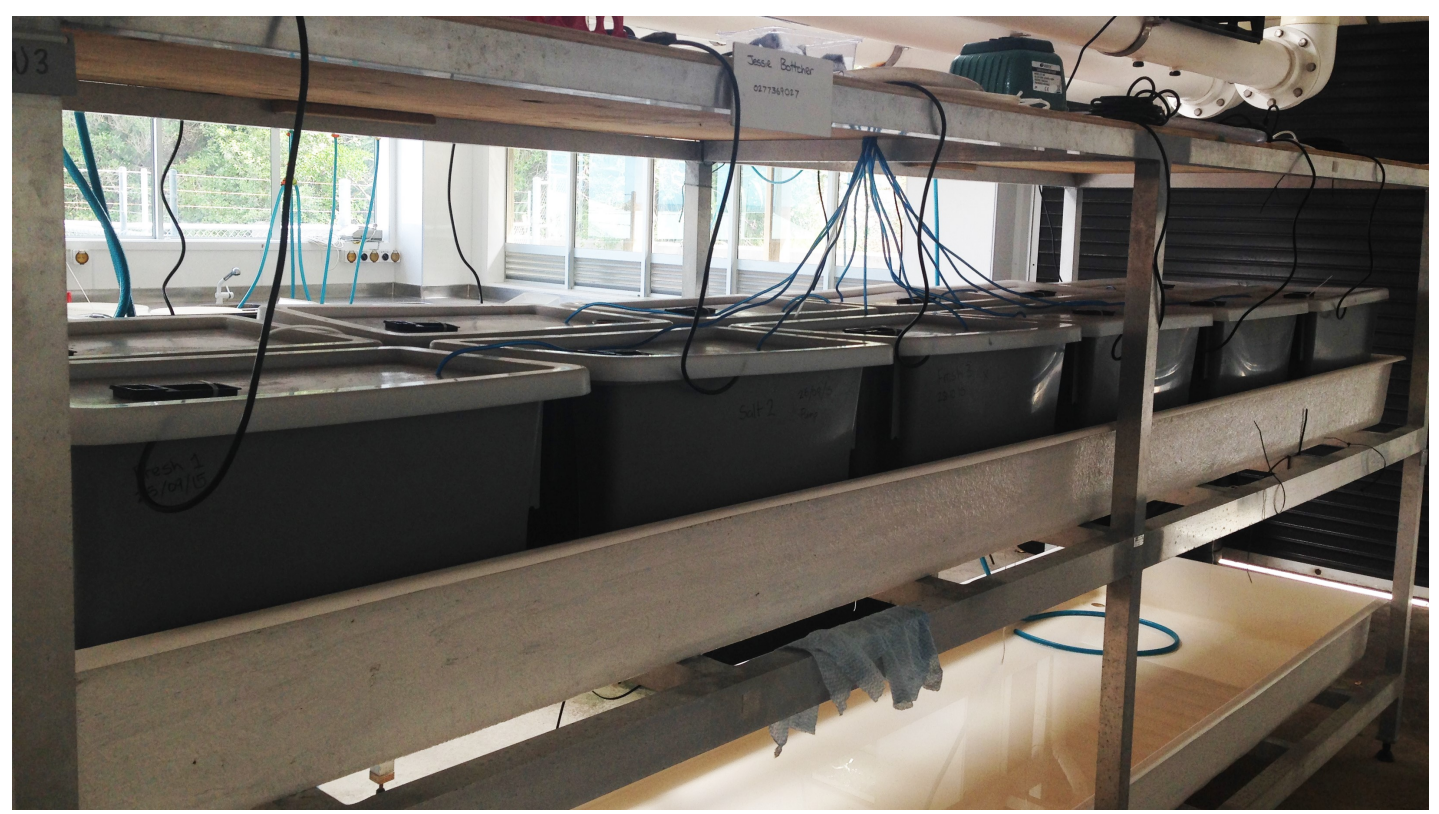

Figure 3.2: Layout of growth manipulation expermient, 8 bins containing 10 recently settled common triplefin in either 'high growth' or 'low growth' conditions. Photo credit: Ben Moginie

standard length ${ }^{3}$, [Ricker, 1975]), and post-settlement growth rates as the change in mean standard length over the 35 growth regime.

\subsubsection{Estimating pelagic larval duration and lifetime growth rates}

To reconstruct individual life history characteristics (i.e., pelagic larval duration and growth rate assessed over the lifespan of an individual) I analysed fish otoliths . For each fish, I extracted sagittal otoliths and immersed them in 15\% mol $\mathrm{H}_{2} \mathrm{O}_{2}$ for 12 hours to remove tissue. I mounted otoliths on plastic discs using a clear resin and hand-polished them with $9 \mu \mathrm{m}$ diamond lapping films $(3 \mathrm{M})$ to reveal daily increments. Otoliths were photographed along the postrostral axis using a Cannon D3-50 through a light microscope (Appendix A). I used Imagepro Premier (Ver. no. 9.1) to count and measure daily growth increments. I identified a 'hatch check' as an approximate doubling in increment width and a 'settlement check' as an approximate halving of increment width accompanied by a visible darkening in increment colour after settlement (Shima and Swearer, 2009). For each fish, I estimated pelagic larval duration ('PLD') as the number of days between the hatch check and the settlement check, and the cumulative 'age' as the PLD combined with number of days since collection (+/- 7 days). I estimated 'mean growth rate' as the standard length divided by 'age'. I validated a sample of my PLD increment counts against those made by a second observer (J.S. Shima); the two independent counts differed by fewer than $3 \%$ 

juvenile reef fish

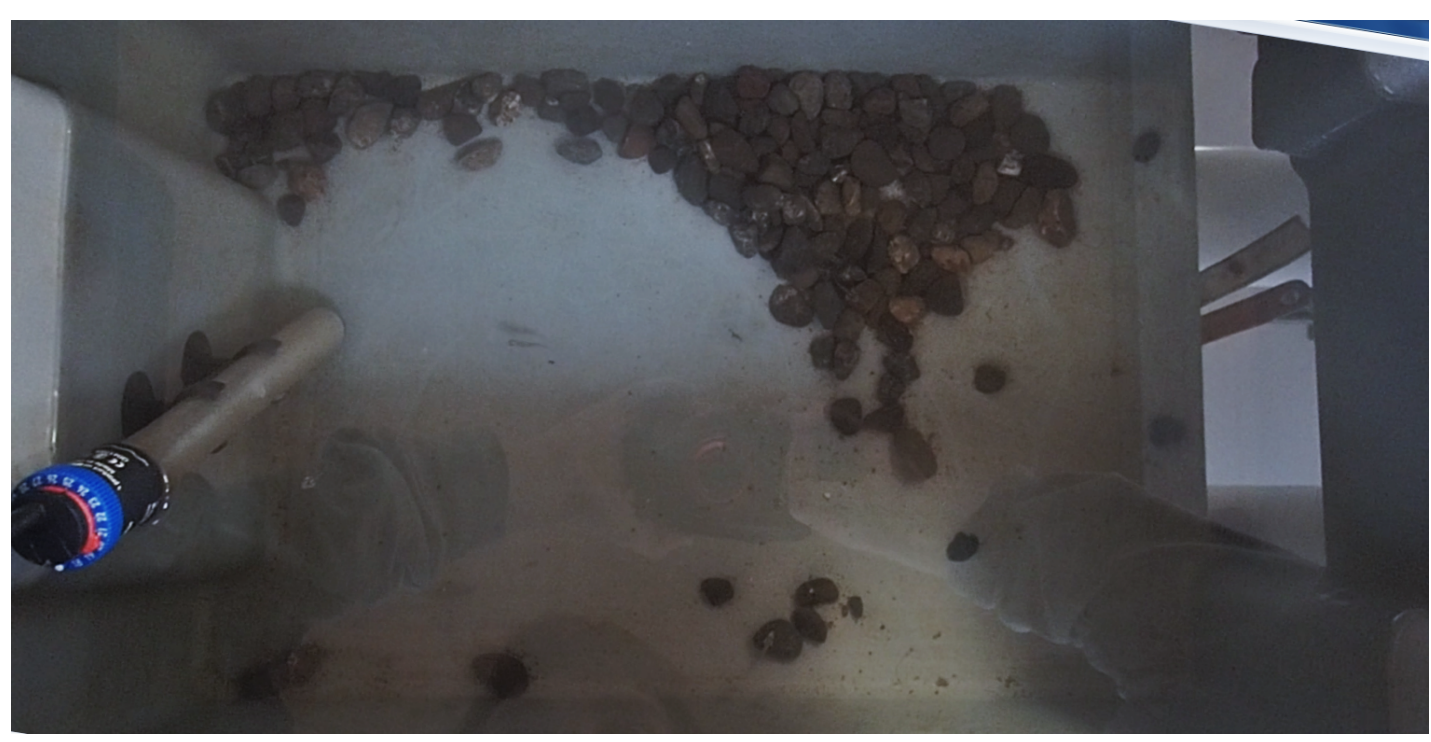

Figure 3.3: Plastic bin contaning 5 juvenile F. lapillum and $400 \mathrm{~cm}^{2}$ of unevenly distributed cobble substrate.

increments on average.

\subsubsection{Assessing competitive ability}

I conducted a set of behavioural assays on experimentally reared fish to assess their ability to secure a resource, as a function of their developmental histories and other individual traits. I evaluated the relationships between: (1) growth environment (i.e., manipulated temperature and feeding regime) on body size and body condition; (2) growth environment, body size, body condition, PLD and average (lifetime) growth rate on resource acquisition ability and, (3) resource acquisition ability on aggressive behaviour.

Assays were conducted on replicate groups of 4 fish ( $n=9$ 'trials' of 4 fish each; 36 fish total) that had access to a single defensible resource. Fish (2 from the high growth treatment; 2 from the low growth treatment) were selected randomly, from different rearing tanks (i.e., the group of 4 fish had no opportunity to interact prior to the assay). Groups of fish were introduced to $60 \mathrm{~L}$ plastic bins filled with seawater maintained at $20^{\circ} \mathrm{C}$, and with a single pile of small cobbles (the defensible resource) positioned in the centre of the tank. Fish were fed ad libitum each day, on a diet of blended frozen mussels.

Fish were given a 3-day acclimation period in trial bins prior to the start of the assay. On day four, I began the assay and made observations every other day over 
the following four days. All fish were uniquely identifiable from variation in natural markings (Thompson, 1986) and on each observation day, I conducted behavioural observations to measure the aggression between fish. On each day, I randomised the order of observations, and observed each fish as a 'focal individual' for a 3 minute duration, recording all agonistic encounters. Specifically, I recorded the frequency of bites and chases (which resulted in evasive behaviour from the recipient) initiated by a focal individual. In all instances, I observed a single fish to be clearly defending the cobble pile. I removed the successful occupant of the resource (i.e., the cobble pile) without replacement and gave the remaining fish $24 \mathrm{hrs}$ to re-acclimate. I sequentially removed the remaining fish identified as 'resource holders' over the next 3 observation days to facilitate a rank-ordering of 'resource occupation' within each trial bin.

\subsubsection{Assessing aggression, territory size and territory quality}

I constructed two mesocosms and used these to evaluate relationships between body size, body condition and aggression on size and quality of territories of sampled fish. Each mesocosm consisted of a plastic bin $\left(45 \mathrm{~cm}^{2} \times 55 \mathrm{~cm}^{2} \times 35 \mathrm{~cm}^{2}\right)$, and to each of these I added an aquarium heater, an aerator, and haphazardly distributed $400 \mathrm{~cm}^{2}$ of small cobble to create a heterogeneous substrate covering $\sim 25 \%$ of the mesocosm floor (Fig. 3.3). To each mesocosm I simultaneously introduced 5 randomly selected juveniles (from collections described above), and allowed the fish to acclimate for 3 days. Fish in both mesocosms were maintained at $20^{\circ} \mathrm{C}$ and fed ad libitum on a daily schedule. I made daily observations and recorded behaviour patterns of all fish over 8 consecutive days using the same methods detailed above (i.e., 3-minute observations of focal individuals, recording chases and bites).

On the final observation day, I estimated the territory size of all focal individuals. I defined territory size as the size of the defended area (i.e., the furthest distance a focal individual could travel in any direction before being chased by another individual [Maher and Lott, 1995]). I collected a video record of fish movements and behavioural interactions in each mesocosm for a 15 minute period with a Cannon TG-03 mounted directly above each mesocosm. I used ImageJ (Ver.1.48) to calculate territory area based on a polygon created from all the furthest points an individual was observed to travel without initiating a chase from a neighbouring fish. I defined territory quality as the percent cover of cobble in an individual's defended area. After the video recordings, I measured standard length of all fish using callipers and 
body condition as Fulton's K.

\subsubsection{Statisitcial analyses}

To analyse the effects of developmental environment on body size and condition, I conducted a pair of one-way ANOVAs on average standard length and condition of fish reared in 'high growth treatment' or 'low growth treatment' bins (i.e., I treated 'growth bin' as the replicate, with $n=4$ per treatment).

To determine the effects of treatment, standard length, PLD, growth rate and body condition on the likelihood of occupying a limited habitat resource, I fitted all variables to a cumulative odds ordinal logistic model with proportional odds. I could not successfully fit 'trial' as a random effect to the model. Therefore, to enable comparison among individuals of separate 'trials' I centred the variables within trials around a mean of 0 , then pooled the data among trials.

I then performed a model selection procedure to identify combinations of variables best explained variation in occupation rank using AICc values (Akaike Information Criterion corrected for small sample sizes). Collinearity between two continuous predictors, standard length and growth rate, prevented the inclusion of both parameters in the same model. Consequently, I constructed two sets of 'global models': one including standard length and the other including growth rate. I then compared the fit of each model including either standard length or growth rate. The best fitted model was defined as having a $\Delta$ AICc $<2$. (Burnham and Anderson, 2002). I calculated confidence intervals (from the $t$ distribution) for the parameter estimates in the final model. If the intervals of a parameter included 0 , the parameter was considered non-significant.

To analyse the relationship between 'success' and aggression of juveniles. I performed set of one way ANOVAs to compare the mean rate of aggressive encounters between individuals of different occupation rank. Significant relationships were followed by Tukey tests.

Finally, to investigate if larger, better condition and/or more aggressive, juveniles acquired territories that are of higher quality, I conducted a series of linear models. In each model I added 'mesocosm' as a blocking factor to statistically adjust for differences between mesocosms.

Additionally, I performed a repeated measures ANOVA to investigate if rate of aggression (i.e., the number chases in 3 minutes) varied over the 8 day period after 
statistically accounting for variation between individual fish.

All statistical procedures were performed using $R$ Statistical Software V. 3.2.2. ( $R$ Core Team 2015). The cumulative odds ordinal logistic regression with proportional odds was run using the 'MASS' package (Ripley et al., 2015) and the function 'polr'. Models and associated AICc values were created using the package 'MuMIn' (Barton, 2015). 


\subsection{Results}

\subsubsection{Developmental environment on juvenile body size and condition}

Standard lengths of juveniles ranged from 18.06 to $31.44 \mathrm{~mm}$ and did not differ between juveniles reared in 'high' and 'low' growth treatments $\left(F_{1,6}: 0.7434, \mathrm{P}: 0.4217\right.$, Fig. 3.4). Body condition (Fulton's $\mathrm{K}$ ) ranged from $1.05 \times 10^{-5}$ to $1.52 \times 10^{-5}$ and did not differ statistically between fish reared in 'high' and 'low' growth treatments $\left(F_{1,6}\right.$ : 0.0087, P: 0.9285). Mortality was substantially higher for juveniles reared in the low growth treatment $(52.5 \%)$ compared with juveniles reared in the high growth treatment $(12.5 \%)$ over the 35 day period.
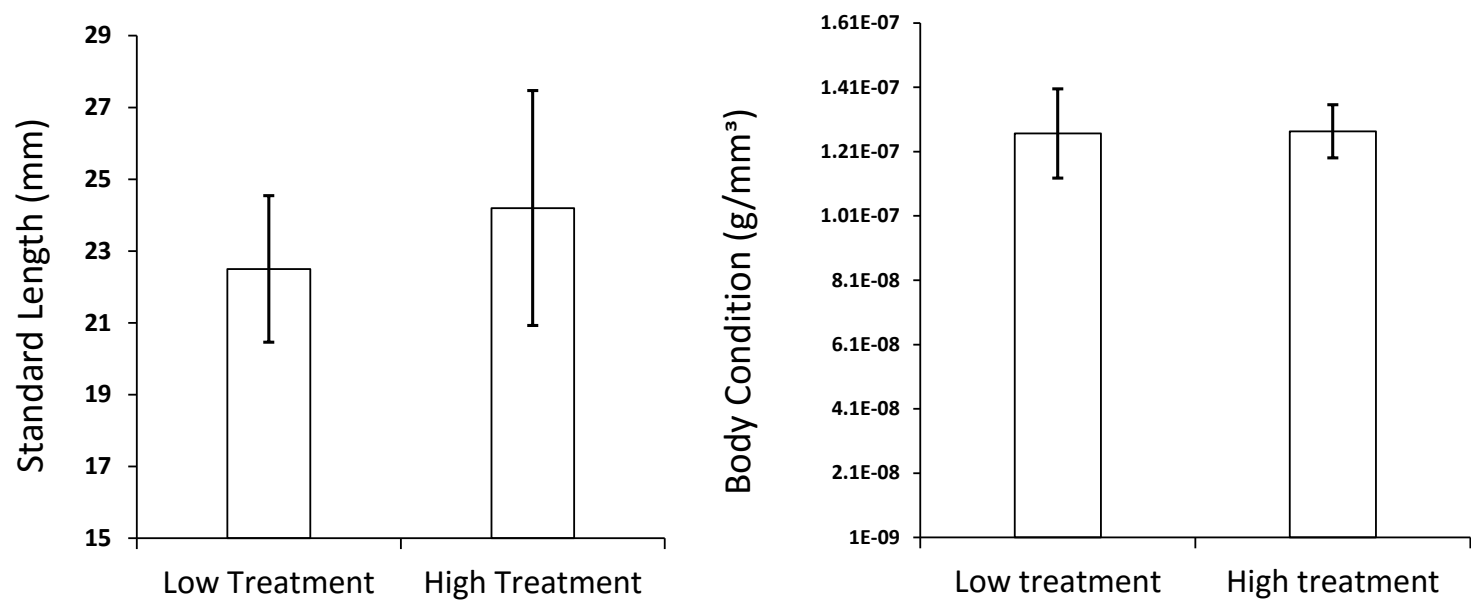

Figure 3.4: Comparison of mean standard length and body condition for juveniles reared in 'high' and 'low' growth treatments Response axes are offset from 0 for graphical presentation. Error bars represent $95 \%$ confidence intervals.

\subsubsection{Reconstructing life history traits}

I successfully resolved daily increment counts between the 'hatch check' and 'settlement check' from the otoliths of all 36 juveniles used in the resource occupation trials. This enabled me to reconstruct the PLDs and mean growth rates for each individual. Pelagic larval durations ranged from 34 to 56 days (mean: 45.8, SD: 4.28) and mean growth rates ranged from $0.209-0.293 \mathrm{~mm} /$ day (mean: 0.252, SD: 0.02). 


\subsubsection{Predictors of resource occupation}

The best model to account for variation in occupation rank included growth rate, PLD, and body condition (Tab. 3.1). The final model was a better fit than the second best model by a $\Delta$ AICc value of 2.81 . The variable 'treatment' did not contribute to the final model. In general, models including growth rate outperformed models including standard length (Tab. 3.1).

Parameter estimates from the final model suggest juveniles that grow $0.01 \mathrm{~mm} /$ day faster relative to conspecifics, become 4.8 times more likely (95\% CI: $2.25,6.99)$ to increase in occupation rank. Similarly, juveniles that spend one day longer in the pelagic larval stage (i.e., a one day increase in PLD) relative to conspecifics, become 1.7 times more likely $(95 \%$ CI: $0.37,3.03)$ to increase in occupation rank. The estimate of body condition displayed confidence intervals that overlapped 0 (95\% CI: -1.94, $2.68)$, therefore, the effects of body condition on resource occupation were considered non-significant.

\subsubsection{Effect of resource occupation on aggression}

During the first set of observations, all four fish were present in the trial and the mean rate of aggressive interactions varied between individuals of different ranks $\left(F_{3,32}: 13.233, \mathrm{P}<0.001\right)$. The fish occupying the resource (rank 1$)$ were more aggressive than the three fish not occupying the resource (Fig. 3.5i).

I performed a second set of observations, after removal of the 'rank 1' fish. Here, the mean rate of aggressive interactions also varied between individuals of different rank $\left(F_{2,24}: 8.89\right.$, P: 0.001;). The new occupants of the resource (rank 2$)$ were significantly more aggressive than the other two fish not occupying the resource (Fig.3.5ii).

I removed the 'rank 2' fish, and performed a final set of observations. Here, the mean rate of aggressive interactions did not differ between the new resource occupant (rank 3$)$ and the last remaining fish $\left(F_{1,16}: 2.65\right.$, P: 0.123; Fig. 3.5iii). 
Table 3.1: Comparison of models derived from 'global models' containing either standard length or average growth rate, in addition to the PLD, growth treatment and body condition using AICc. $\triangle \mathrm{i}$ represents the difference in AICc values between model $i$ and the best fitted model, $\omega$ represents the Akaike weight. Bold text signifies the best fitted model from each of the global models.

\begin{tabular}{llllll} 
Factors in the model & Deviance & K & AICc & $\Delta \mathbf{i}$ & $\omega$ \\
\hline Model including growth rate & & & & & \\
Growth rate + Cond. + PLD + Treatment & 72.95 & 7 & 90.95 & 2.81 & 0.166045 \\
Growth rate + Cond. + PLD & 73.24 & $\mathbf{6}$ & $\mathbf{8 8 . 1 4}$ & $\mathbf{0}$ & $\mathbf{0 . 6 7 6 7 2}$ \\
Growth rate + Cond. + Treatment & 91.67 & 6 & 106.57 & 18.43 & $6.74 \mathrm{E}-05$ \\
Growth rate + PLD + Treatment & 79.02 & 6 & 93.91 & 5.77 & 0.037798 \\
Growth rate + Cond. & 91.89 & 5 & 103.89 & 15.75 & 0.000257 \\
Growth rate + PLD & 79.63 & 5 & 91.64 & 3.5 & 0.117596 \\
Growth rate + Treatment & 91.72 & 5 & 103.71 & 15.57 & 0.000281 \\
Growth rate & 91.96 & 4 & 101.25 & 13.11 & 0.000963 \\
PLD + Cond. & 96.49 & 5 & 108.49 & 21.54 & $1.25 \mathrm{E}-05$ \\
PLD + Treatment & 96.49 & 5 & 108.49 & 21.54 & $1.25 \mathrm{E}-05$ \\
Cond. Treatment & 99.55 & 5 & 111.55 & 24.6 & $2.71 \mathrm{E}-06$ \\
PLD & 96.49 & 4 & 105.79 & 18.84 & $4.83 \mathrm{E}-05$ \\
Cond. & 99.55 & 4 & 108.85 & 21.9 & $1.05 \mathrm{E}-05$ \\
Treatment & 99.8 & 4 & 109.1 & 22.15 & $9.22 \mathrm{E}-06$ \\
NULL & 99.81 & 3 & 106.56 & 19.61 & $3.28 \mathrm{E}-05$ \\
& & & & & \\
Model including standard length & & & & & \\
Std. length + Cond. + PLD + Treatment & 89.68 & 7 & 107.68 & 4.9 & 0.023369 \\
Std. length + Cond. + PLD & 89.88 & 6 & 104.78 & 2 & 0.099623 \\
Std. length + Cond. + Treatment & 91.83 & 6 & 106.73 & 3.95 & 0.037577 \\
Std. length + PLD + Treatment & 91.76 & 6 & 106.66 & 3.88 & 0.038915 \\
Cond. + PLD + Treatment & 96.48 & 6 & 111.38 & 24.43 & $2.95 \mathrm{E}-06$ \\
Std. length + Cond. & 92.15 & 5 & 104.15 & 1.37 & 0.136509 \\
Std. length + PLD & 91.99 & 5 & 103.99 & 1.21 & 0.147878 \\
Std. length + Treatment & 93.18 & 5 & 105.18 & 2.4 & 0.081564 \\
PLD + Cond. & 96.49 & 5 & 108.49 & 21.54 & $1.25 \mathrm{E}-05$ \\
PLD + Treatment & 96.49 & 5 & 108.49 & 21.54 & $1.25 \mathrm{E}-05$ \\
Cond. + Treatment & 99.55 & 5 & 111.55 & 24.6 & $2.71 \mathrm{E}-06$ \\
Std. length & $\mathbf{9 3 . 4 9}$ & $\mathbf{4}$ & $\mathbf{1 0 2 . 7 8}$ & $\mathbf{0}$ & $\mathbf{0 . 2 7 0 8 0 2}$ \\
PLD & 96.49 & 4 & 105.79 & 18.84 & $4.83 \mathrm{E}-05$ \\
Cond. & 99.55 & 4 & 108.85 & 21.9 & $1.05 \mathrm{E}-05$ \\
Treatment & 99.8 & 4 & 109.1 & 22.15 & $9.22 \mathrm{E}-06$ \\
NULL & 99.81 & 3 & 106.56 & 19.61 & $3.28 \mathrm{E}-05$
\end{tabular}



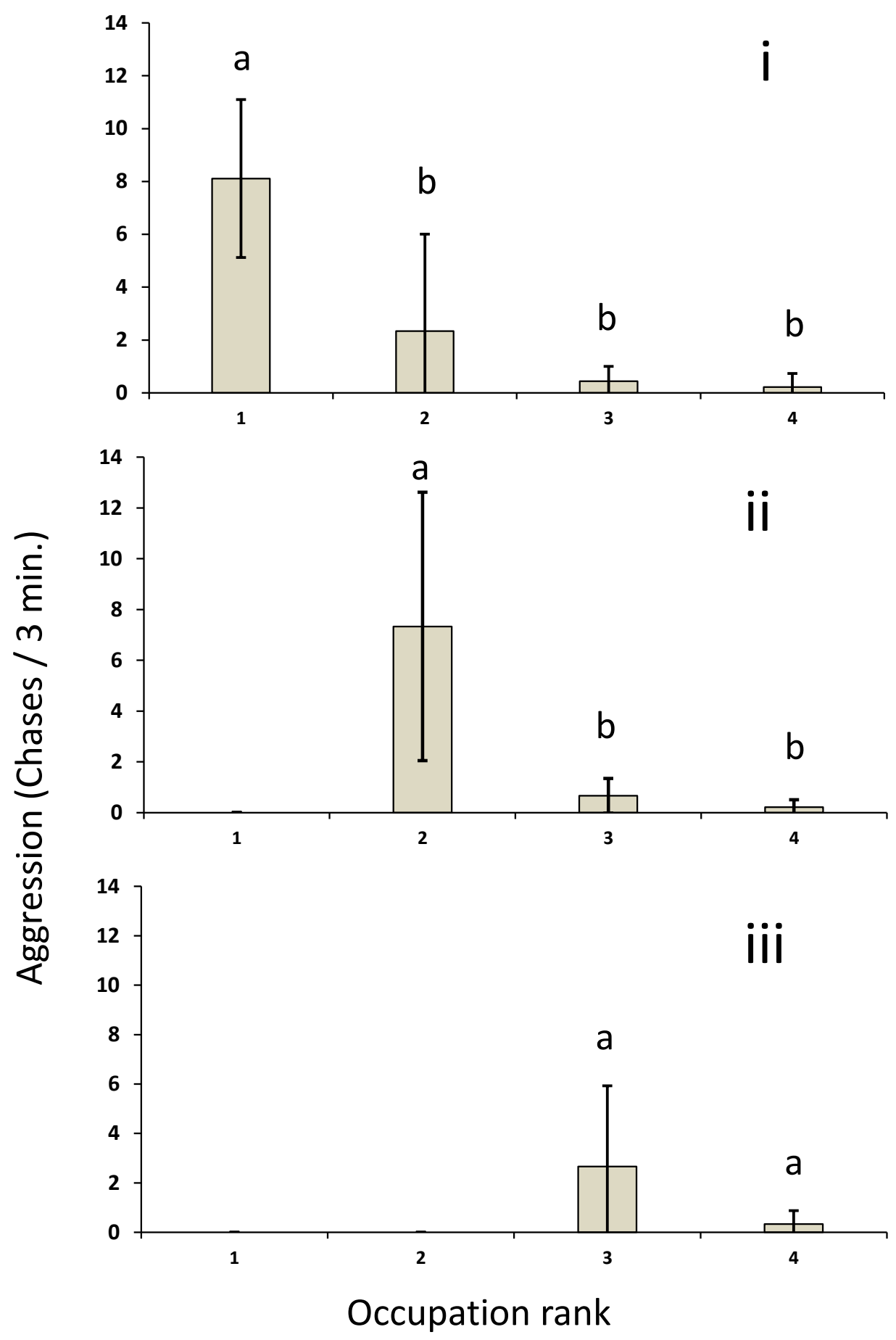

Figure 3.5: Mean number of aggressive actions for fish of each occupation rank $(1,2,3$ and 4) when all ranks are present (i), after the sequential removal of the first occupant (ii) and second occupant (iii). Letters $(a, b)$ represent groupings based on Tukey test $(\alpha: 0.05)$. Error bars reperesent $95 \%$ confidence intervals. 


\subsubsection{Predictors of juvenile territory size and quality}

In this observational experiment, the number of aggressive interactions of recently settled juvenile fish ranged from 0 - 20 per 3 minute period (mean: 3.1, SD: 1.8). For each fish, the number of aggressive interactions did not vary significantly between days (repeated measures ANOVA: $F_{7,63}: 1.8069$, P: 0.1012). Given the number of aggressive actions did not vary over time, I proceeded to compare territory size and quality to the average number of aggressive actions for each fish over the 8 day period.

Figure 3.6 illustrates that average aggression score, standard length and body condition were all positively correlated to increased territory size and quality. The linear models suggested variation territory size and quality was significantly predicted by body size and aggression but not body condition (Tab. 3.2).

Table 3.2: Linear relationships between the predictor variables 'Average aggresion', 'Standard length' and 'Body condition', and repsonse variables 'Territory size' and 'Territory quality' after blocking for the effect of 'mesocosm'. Bold $\mathrm{p}$ values represent significance at an $\alpha$ of 0.05

\begin{tabular}{|c|c|c|c|c|c|}
\hline Response variable & Predictor variable & Coefficient estimate & $\mathbf{R}^{2}$ & t value & $\mathbf{p}$ \\
\hline & Average aggression & 15629 & 0.6596 & 4.054 & 0.005 \\
\hline \multirow[t]{2}{*}{ Territory size } & Standard length & 13955 & 0.6885 & 4.313 & 0.003 \\
\hline & Body condition & $1.325 \mathrm{e}+10$ & 0.2042 & 1.739 & 0.126 \\
\hline \multirow[t]{3}{*}{ Territory quality } & Average aggression & 5.0628 & 0.8782 & 8.164 & 0.000 \\
\hline & Standard length & 10.264 & 0.4984 & 3.300 & 0.013 \\
\hline & Body condition & $6.009 \mathrm{e}+06$ & 0.6949 & 0.863 & 0.417 \\
\hline
\end{tabular}



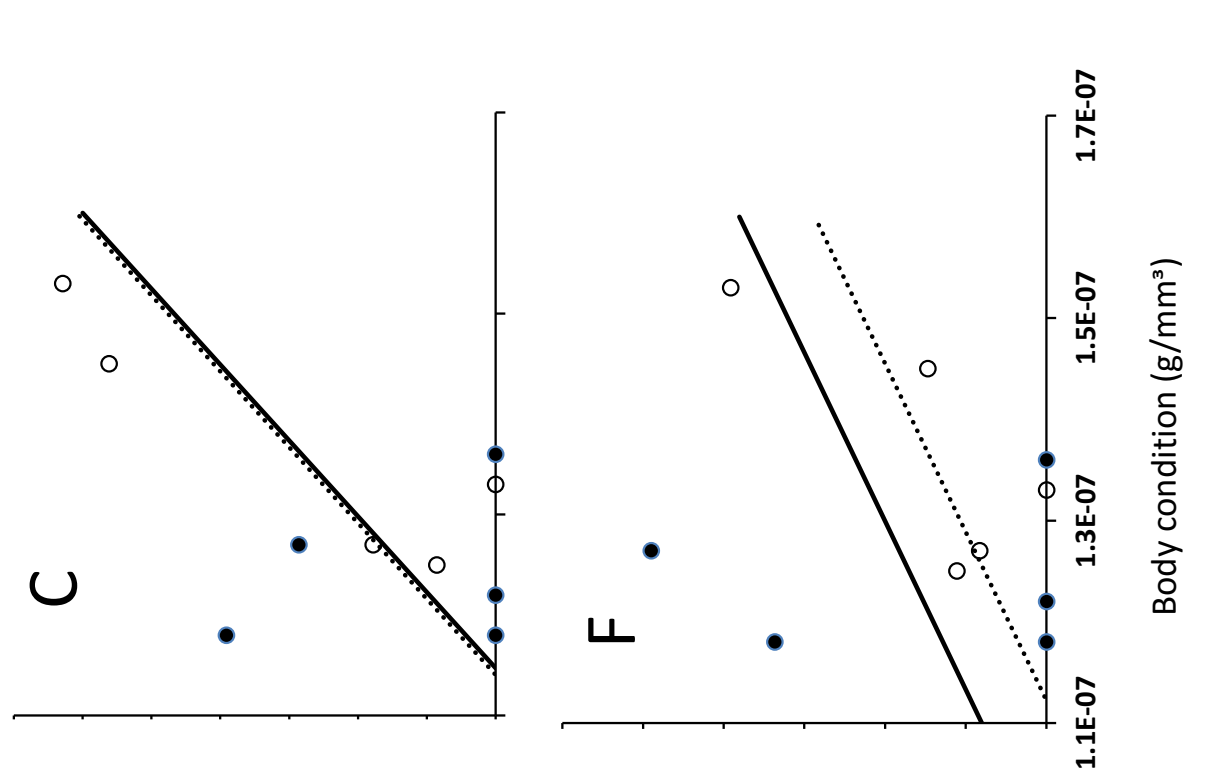

อิ
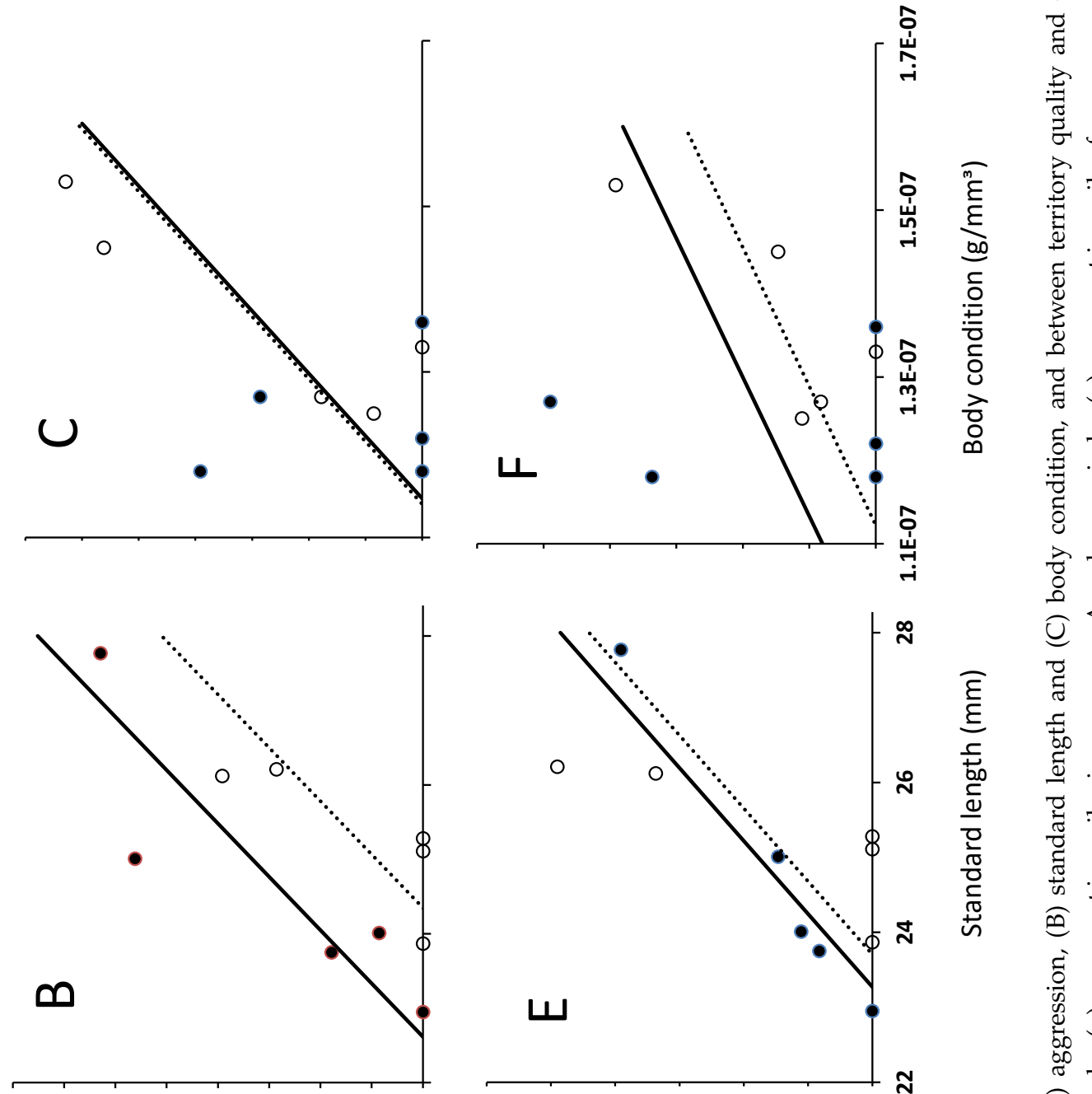

(บ)

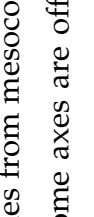
要

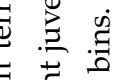

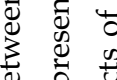
这蒂离 ฮิ 0 हो $\frac{\mathscr{d}}{\mathrm{y}}$ :

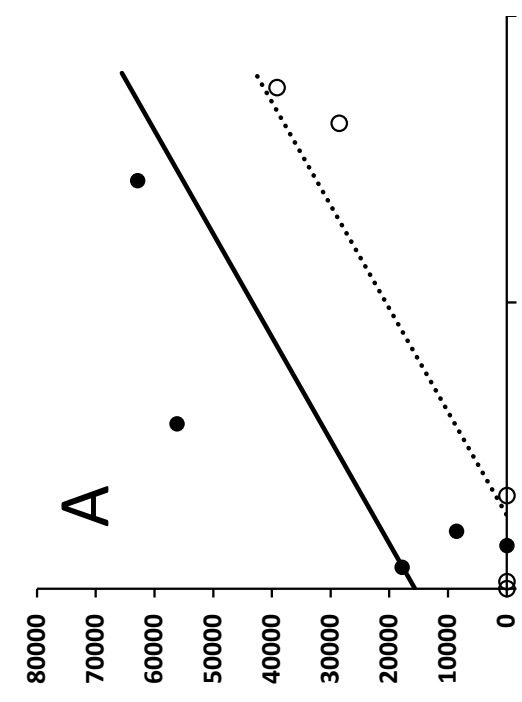

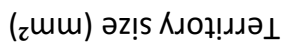

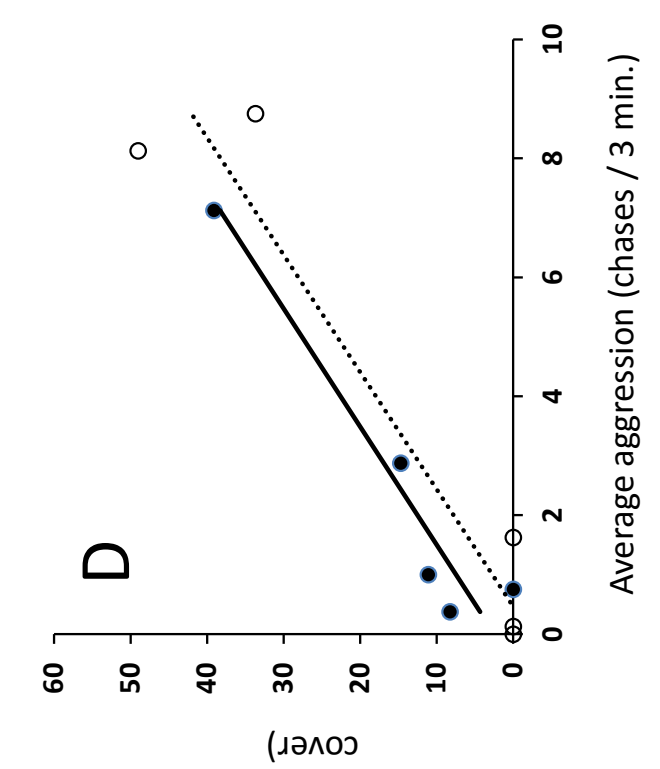

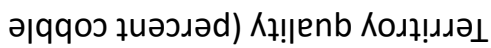

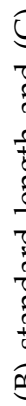

है

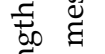

ฮี

흉

劳

谷 节

हี :

过

点

ङ.

를

ปิ

के :

हैं 융

휼 훙

ㄷํㅇ

茎导

¿ ह

争 吉点

究

弚 స

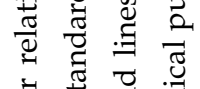

竎 क

寻画芯

ڤே

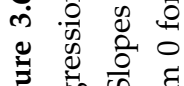

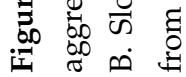




\subsection{Discussion}

Determining stage-specific drivers of success is crucial to our understanding of population dynamics and reproductive success of species with complex life cycles. The life cycle of many marine animals involves the transition from a pelagic larval stage to a benthic juvenile stage. Individuals may experience different conditions after settlement, particularly in complex habitats such as coral or rocky reefs. However, the effects of variable environmental conditions at settlement on future juveniles success are not well studied My results suggest (i) developmental environment after settlement may have limited influence on juvenile growth and phenotype; (ii) life history traits and the resulting phenotypes, may influence the odds of resource occupation by juveniles; (iii) the resource occupation or dominance status of juveniles influences aggressive behaviour, and (iv) when settling onto heterogeneous substrates juvenile body size and aggression, predict the size and quality of established territories. Collectively, these results indicate that a mixture of life history traits, phenotypes and recent environmental experiences may influence individual success (and subsequently, behaviour) in a cohort of recently settled juveniles.

\subsubsection{Treatment effects on growth and size}

Variability in developmental environment after settlement did not appear to influence resulting juvenile phenotype. This results is unexpected and contradicts a wide volume of research that identifies variation in temperature and food availability as drivers of variable growth in fishes (Brett et al., 1969; Angilletta et al., 2004; Matthews and Wong, 2015), even over short time periods (e.g., 5 days, Booth and Beretta, 2004) and small spatial scales (Baltz et al., 1998; Nielsen, 1992).

If variation in recent developmental conditions did not influence juvenile phenotype then, presumably, the common triplefin is capable of regulating the effects of variable temperature and food supply in order to maintain an optimal growth rate. Khan and Herbert (2012) suggest common triplefins are able to regulate their metabolism over a wide range of temperatures $\left(15^{\circ} \mathrm{C}-21^{\circ} \mathrm{C}\right)$, which is understandable in a species that may experience a wide range of thermal environments.

However, the purpose of regulating growth in high food conditions is unclear. Several studies suggest subordinate individuals may 'self-limit' their growth rate to reduce increases in body size which may incite increased aggressive responses from 
nearby dominants (Wong et al., 2008; Ang and Manica, 2010b). In my study, fish were observed forming dominant-subordinate relationships within the treatment bins which, in addition to causing self-limiting growth, may have driven unequal distribution of food resources among individuals in the same bin, increasing the variation of body size and condition within bins (Perrone, 1978; Lee et al., 2011), confounding potential effects of developmental environment.

The effects of developmental environment were further confounded by mortality over the treatment period, particularly in the 'low treatment' bins, where $52.5 \%$ of fish died. Mean body size and body condition of juveniles within low treatment bins may be artificially inflated in response to selective mortality of lower condition or smaller fish. Additionally, mortality may have increased variation between bins which, combined with my small sample size, may have reduced my ability to statistically detect the effects of developmental environment on juvenile phenotype.

\subsubsection{Predicting competitive ability}

The ordinal logistic regression model that best explained juvenile occupation rank, contained only two significant parameters, mean lifetime growth rate and PLD. As expected, mean growth rate was strongly correlated to body size, which suggest mean growth rate may influence the ability of juveniles to occupy a limited resource through proximate effects on body size (Perrone, 1978; Magnhagen and Kvarnemo, 1989; Cutts et al., 1999). In wild populations, larger body sizes may have additional benefits by enabling larger individuals to obtain resources that are unavailable to smaller competitors due to predation risk (Candolin and Voigt, 2001)

Models including mean lifetime growth rate typically outperformed models including body size, suggesting mean lifetime growth rate may have additional effects on the odds of acquiring limited territories other than influencing body size. Non-size related growth effects are not well described in the literature. Some studies suggest accelerated growth rates may influence aggressive behaviour, for example juvenile Atlantic salmon that experienced higher growth conditions were consistently more aggressive than juveniles reared in low growth conditions (Nicieza and Metcalfe, 1999). Alternatively, fish with faster average growth rates may be prone to increased risk-taking behaviour (Stamps, 2007). In my study, increased risk taking behaviour may mean approaching the habitat resource earlier and benefiting from any priority effects (Geange and Stier, 2010). However, if fast growth increases risk taking be- 
haviour then, in wild populations, faster growers may suffer higher mortality due to increased exposure to predators (Biro et al., 2004).

Prolonged PLD may result in larger body sizes at settlement (Wenger et al., 2014), increasing competitive ability at the juvenile life stage, relative to others in the same cohort (Sponaugle et al., 2006). However, the advantages of prolonged larval development may be restricted to relatively nutrient rich environments (e.g., Wellington harbour) and prolonged development in nutrient poor environments may negatively affect the quality of developing larvae (Shima and Swearer, 2009), with potential carry-over effects on juvenile performance (Smith and Shima, 2011).

In the wild, increased size during the larval stage may reduce the risk of predation (i.e., growth-mortality hypothesis [Anderson, 1988; Perez and Munch, 2010]). In which case, increased growth rate and prolonged PLD may increase both survival at settlement and juvenile competitive ability for recently settled fish. However, some studies suggest larger body size at settlement may increase predation risk (Pepin, 1992; Gagliano et al., 2007), including a recent study on the common triplefin by Caie and Shima (unpubl. dat. 2016). If increased size at settlement both (i) decreases survival and (ii) increases competitive ability, then common triplefins may undergo a trade-off between survival and competition at settlement (Fig. 3.7). If this were the case (and a competitive advantage enhanced future reproductive success), then body sizes (and indirectly PLD and growth rate) may be subject to stabilising selection during the ontogenetic shift from the larval to the juvenile life stage.

Additionally, selection may also favour individuals which are able to quickly increase in size (i.e., greatly accelerate growth) immediately after settlement, enabling larvae to reduce predation risk at settlement and increase competitive ability as a juveniles. As my growth treatments were unsuccessful in manipulating juvenile growth or phenotype, further research is needed to address this issue.

Growth treatment (i.e., development environment) did not contribute significantly to the best fitted model. Given no treatment effects were detected on juveniles phenotype, this result is not entirely surprising. In addition, Hsu et al. (2006) suggest outcomes of previous competitive interactions (i.e., interactions that may have occurred in growth bins) may also affect future competitive ability (i.e., in the resource occupation trials), further confounding potential treatment effects. Finally, treatment (or body condition) may have had subtle effects on juvenile competitive ability that were not detected given the small sample size (i.e., low statistical power) of the model. 


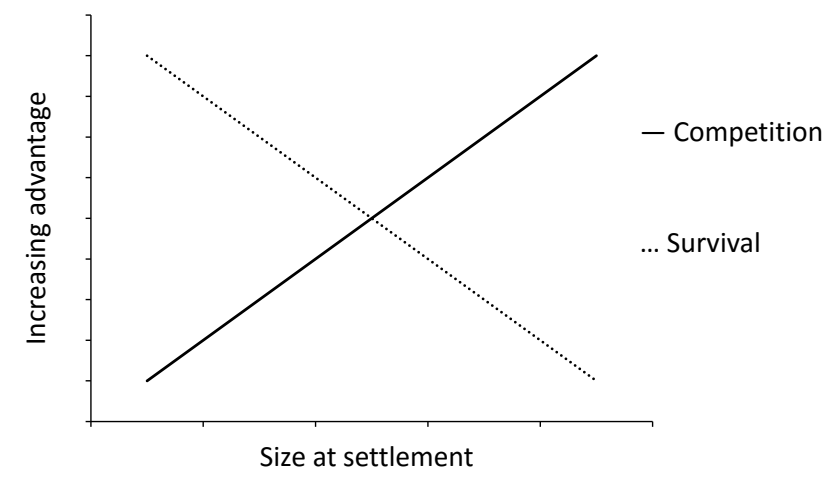

Figure 3.7: A simple conceptual model of the trade-off of the effects of body size on survival and compeititon for settling common triplefin.

\subsubsection{Competitive ability and individual aggression}

Individual aggressive behaviour often increases with competitive ability (Cutts et al., 1999; Nicieza and Metcalfe, 1999), but the direction of the relationship is rarely tested (i.e., whether aggression predict competitive ability or vice-versa). My results suggest (1) resource occupants engage more frequently in aggressive interactions than non-occupants and (2) new occupants become more aggressive to their remaining competitors after the previous occupant has been removed. The increase of aggression by new occupants suggests that aggression may be a plastic response that increases when an individual acquires a valuable resource (or when a dominant individual is removed). This result supports the prediction of game theory; that individuals increase their investment in fighting ability relative to the value of the resources under their control (Enquist and Leimar, 1987).

Other territorial fishes also exhibit this behaviour, for example O'Connor et al. (2015) found African cichlids that usurped the territory of a displaced competitor were much less likely to return to the territory when the original occupant was returned, and become increasing less likely to return the territory over time. Additionally, the act of 'winning' aggressive encounters (i.e., forcing the opponent to retreat) may increase future fighting ability or the willingness to engage in future aggressive encounters (Fuxjager et al., 2010), and may suppress aggressive behaviour by sub-ordinates (Bshary and Lamprecht, 1994). 
However, I did not detect any statistical differences in aggression when only the third and fourth ranked fish were present, possibly due the limited sample sizes ( $\mathrm{n}=9$ bins) or the reduced number of interactions between fish associated with decreasing fish density.

\subsubsection{Effects of phenotype and aggression on territory distriubtion}

For territoriality to evolve within a species, the advantages of acquiring a territory must outweigh the costs of defence (Ah-King et al., 2005). Establishing large territories, for example, may increase access to food resources (e.g., Cutts et al., 1999). Juvenile common triplefins are largely sedentary and often feed on drifting organic matter or invertebrates suspended in the water column (Mensink and Shima, 2015). Thus a larger territory size may mean access to larger volume of food resources, facilitating faster growth and increased body size (Cutts et al., 1999). Individuals with better quality territories (in terms of percent cobble cover), may benefit from increased protection from predators (Connell and Jones, 1991), priority of access to food resources (in environments with 'patchy' food availability [Nielsen, 1992]) or, for males, a suitable nesting site to attract females at the onset of the breeding season (Francis, 2001).

The spatial distribution of territorial individuals is expected to be a function of their relative competitive abilities (Parker and Sutherland, 1986). So far, this study has suggested individual competitive ability increases with aggression and body size (as a function of lifetime growth and PLD), but not body condition. My results suggest the size and quality of established territories are predicted by individual aggression and body size, but not body condition; reflecting the drivers of individual competitive ability.

The significant relationships between body size and both territory size quality, reinforces the importance of body size as a determinant of competitive ability. Furthermore, it suggests the spatial distribution of juveniles in a heterogeneous benthic environment may vary as a function of relative phenotypes and underlying life history drivers.

The significant relationships between aggression and both territory size quality, however, may be a response of territory acquisition, rather than a predictor.

The observed relationship between aggression and territory size may be an artefact of the limited space within the mesocosm (i.e., intruders are more likely to enter a larger territory than a smaller territory by chance). In addition, the frequency of ag- 
gressive interactions in each mesocosm may be inflated compared wild populations, where sub-ordinates may distance themselves from immediate dominants to reduce aggression (Drews, 1993; Ang and Manica, 2010a).

\subsubsection{Conclusion}

Overall, this study suggests (i) developmental environment may have a limited influence on the phenotype of recently settled juvenile triplefins; (ii) life history traits (PLD and mean lifetime growth rate) predict individual 'success' at the juvenile life; (iii) individuals increase their aggression relative to their 'success', and, (iv) fish that are more aggressive, larger in body size, but not in better condition, establish bigger and better quality territories. Determining the drivers of success at crucial life stages are vital to our understanding of population dynamics of reef fish. This study highlights the importance of life history characteristics (e.g., lifetime growth and PLD) that may drive phenotypic variation in studies of success and emphasises the interplay between life history, phenotype and social dynamics on the success of settling juveniles. 


\section{CHAPTER 4}

\section{General discussion}

\subsection{Overview}

Evolutionary theory is based on the concept that individuals vary in their reproductive success (Williams, 1992; Andersson, 1994). Yet, the determinants of success for systems featuring male parental care are not well defined, particularly in species with complex life cycles, where the drivers of success may vary with ontogeny (Werner and Gilliam, 1984; Gagliano et al., 2007).

The overarching aims of this thesis were identify determinants of (i) reproductive success of adult males and (ii) territory establishment of recently settled juveniles in a system featuring male parental care. Particular focus was placed on the influence of life history characteristics including timing of hatch, growth during development and pelagic larval duration. I addressed these aims using a combination of observational field studies and manipulative laboratory experiments on a species of rocky reef fish that exhibits male parental care, the common triplefin, Forsterygion lapillum. My results have revealed the importance of investigating multiple determinants of success, and the particular influence of life history characteristics (e.g., growth rates, hatch dates and larval development duration) in studies of success at different life stages. My work indicates distinct life-history pathways that can predict success through their influence on individual phenotypes. This research builds upon a growing base of literature investigating the determinants of success in systems with male parental care, and stimulates new questions about the roles of developmental history on reproductive success.

\subsection{Determining success}

\subsubsection{Adult males}

Selection favours individuals with traits that enhance reproductive success (Andersson, 1994). Theory suggests that, in systems with male parental care, male reproductive success is dependant on territoriality and female choice (Blumer, 1979; Gross and Sargent, 1985; Ah-King et al., 2005). In chapter 2, I sampled a wild population of adult male F. lapillum and found territoriality was predicted by body size, and 
female choice (i.e., egg presence or absence) was predicted by body condition. My otolith-based reconstructions of life history traits suggest two alternative pathways to male 'success'. First, through early hatching date, and secondly, by fast growth during development.

The relationship between body size and territoriality is in line with a large volume of research that links increased body size to enhanced competitive ability (Jarvi, 1990; Schuett, 1997; McElligott et al., 2001). However, unlike many other species body size did not predict female choice (i.e., the presence or absence of eggs in a male's territory), Instead, differences in body condition explained the presence or absence of eggs within male territories. Females may have evolved to select for males with higher body condition for a variety of reasons. The literature suggests males with increased body condition may be less prone to filial cannibalism (Vinyoles et al., 1999; Gomagano and Kohda, 2008) or less likely to abandon the clutch in search of food (Côte and Hunte, 1989) - both of which may increase the survival of eggs under male care.

Selection for enlarged body size and, upon establishing a territory, increased body condition, suggests males with developmental histories that promote enlarged body size and increased body condition may experience greater reproductive success. Investigation into life history characteristics revealed there are multiple life history pathways to reproductive success for adult male common triplefins.

A key pathway was through early hatch date. Territorial males tended to be born earlier than floater males and, among the territorial males, those with eggs hatched earlier than those without eggs. This result suggests there may be directional selection for earlier hatching individuals, and thus selection for early mating of adult females. To my knowledge, very few studies have identified this pattern in fishes (but see Fagundes et al., 2015), however directional selection for earlier hatch dates has been identified in nesting birds (Verhulst and Nilsson, 2008; Thorley and Lord, 2015). Selection may favour early hatching individuals for several reasons. In birds, for example, early hatching date may influence success by increasing mating experience or territory quality (Thorley and Lord, 2015). However, earlier hatching individuals may also get a 'head start' on the development of phenotypic traits that enhance competition or mate attraction; benefit from priority effects (e.g., Geange and Stier, 2010); or reach sexual maturation earlier.

My study also revealed a secondary pathway to reproductive success - increased growth rate. Fast growth during development appeared to increase the success of 
later hatched fish, thus mediating the negative effects of a later hatching date. Fast growth rates may accelerate the development individual body size and condition, thus increasing male competitive ability and sexual attractiveness relative to slow growers hatched during the same month (Walling et al., 2007).

The importance of early hatch dates and fast growth rates imply populations of adult common triplefin are shaped by (1) maternal effects (i.e., the timing of oviposition by females) and (2) genetic or environmental influences on individual growth rates. Future research investigating the reproductive timing of adult females, and manipulative studies on individual growth rates would be useful to gain a fuller understanding of reproductive success and the consequences on population dynamics.

Additionally, some populations of common triplefin in the northern regions of $\mathrm{New}$ Zealand reproduce year-round (Wellenreuther and Clements, 2007b), thus the life history pathways that determine success may differ to those discovered in my study. Investigation into the life history pathways that determine success for those populations would provide valuable insight into the influence of life history on the shape and structure of different populations.

\subsubsection{Recently settled juveniles}

Territorial reef fish often settle onto complex habitats which may induce differences in growth and phenotype between neighbouring individuals (Nielsen, 1992; Baltz et al., 1998; Munday, 2001; Wehrberger and Herler, 2014). Phenotypic and behavioural variation are theorised to predict the outcomes of competitive interactions for limited resources (e.g., bigger or better quality territories). In chapter 3, I reared a cohort of recently settled common triplefins in different developmental environments and investigated the effects of developmental environment, phenotype and life history on juvenile 'success' (i.e., their ability to secure limited and high quality territories).

Previous research has suggested even minor fluctuations in food availability or temperature may influence somatic growth (and resulting phenotype) in young fishes (e.g., Booth and Beretta, 2004). My research contradicts this theory, suggesting the common triplefin may have evolved mechanisms to regulate growth over variable temperatures and food supply (Khan and Herbert, 2012). The advantages of restricting growth in favourable growing environments (e.g., warm temperature and high food supply) are not well documented in the literature. Some studies suggest accelerated growth, particularly during early life stages may have negative consequences 
for future reproductive success, such as decreased reproductive output (Auer et al., 2010), or reduced longevity (reviewed in Metcalfe and Monaghan, 2003). However, the results of chapter 2 suggest accelerated growth could be a pathway to enhanced reproductive success in the common triplefin.

Conceivably, the effects of developmental environment on growth may have been masked by the social hierarchies established within treatment bins. Wong et al. (2008) and, Ang and Manica (2010b) suggest 'self-limited' growth may have evolved as a mechanism by subordinate individuals to reduce aggression from immediate dominants. Future studies attempting to identify the effects of variable development environments on individual growth should consider rearing fish in isolation to control for potential social influences on individual growth.

While the influence of developmental environment on juvenile phenotype remains unclear, my results highlight the importance of larval experiences (i.e., pelagic larval duration and somatic growth) on juvenile success. The importance of early life history of future survival and success is increasingly recognised in the literature (e.g., Metcalfe and Monaghan, 2001; Lee et al., 2012, 2014). For example, a recent study by Shima et al. (2015) suggest larval dispersal pathways of the common triplefin influence phenotypes and growth after settlement, my results support their notion indicating strong implications of growth and larval duration on the phenotypes, behaviour and performance of recently settled juveniles.

My research also identifies a potential trade-off between survival and competitive ability at settlement for the common triplefin. The literature is conflicting over the survival advantages of large body size at settlement (Anderson, 1988; Pepin, 1992; Gagliano et al., 2007; Perez and Munch, 2010). However, in the common triplefin, large body size and accelerated larval growth are suggested to increase chances of mortality during early life stages (Caie and Shima, unpub. dat. 2016), yet my results suggest these traits also increase juvenile competitive ability. Provided that increased competitive ability leads to increased reproductive success, this would suggest common triplefins undergo stabilising selection for body size at settlement. Additionally, selection may favour triplefins that are able to rapidly increase in size immediately after settlement (thus increasing their competitive ability as juveniles without compromising survival at settlement). Other studies, such as Gagliano et al. (2007), suggest selective forces on the size of young fish may change with ontogeny, therefore selection may favour individuals with 'flexible' growth that are able to adapt to changing selective pressures (Gagliano and McCormick, 2007). To iden- 
tify which growth trajectories lead to reproductive success in the common triplefin would require the repeated sampling of growth histories from a cohort throughout multiple life stages (i.e., from larvae to reproducing adults). This would provide valuable information on the selective pressures associated with ontogenetic shifts and, consequently, the population dynamics of the species.

This study also highlighted the strong effects of juvenile success on the social dynamics of recently settled triplefin. In theory, energetic investment in defence is expected to increase relative to the value of a given resource (Smith, 1979). Several studies across a range of species have observed a positive relationship between individual aggression and territory size or quality (e.g., Lindström, 1992; Cutts et al., 1999; O'Connor et al., 2015). My results add to this base of knowledge, further suggesting that the distribution of territories of variable size and quality is predicted by individual life history (i.e., growth and PLD) through proximate effects on individual phenotype.

This study reveals several directions for future research, namely: (i) the role of variable life history pathways on the success of individuals that settle into different populations; (ii) the consequences of selective pressure for growth plasticity on population structure and, (iii) the implications of social dynamics on future reproductive success in densely populated benthic fishes.

\subsection{Limitations}

Due to time restraints, I was only able to sample one population of adult males over a single breeding season. As such, the life history pathways I observed may not have the same influence on male success in other populations or in future breeding seasons. Additionally, the 'snapshot' sampling design did not account for variation in individual success over the breeding season. The sample sizes of the life history traits I reconstructed in chapter 2, were limited by imperfections in the otoliths of adult males. These small sample sizes may have impaired the ability of statistical tests to detect differences in growth rates that may have been present between floater and territorial males born in the same month.

My results in chapter 3 were subject to a series of potentially limiting factors. Firstly, the power of my statistical analyses were limited by small sample sizes. Small samples sizes may have (i) affected my ability to detect differences in phenotype induced 
by different developmental environments $(n=4)$; affected the confidence intervals of the parameter estimates of the best fitted model $(n=9)$ and, (iii) reduced the accuracy of the liner relationships between territory size and quality and the predictor variables $(n=5)$.

Additionally, the high levels of mortality for fish in the 'low growth' treatment may have influenced the mean body size and body condition of individuals within treatment bins, thus confounding potential treatment effects. To investigate whether there was selective mortality for particular size classes of 'low treatment' juveniles I performed a chi-square test on the distribution of size classes of juveniles, using scaled photos of juveniles taken before and after the rearing experiment. The test suggested the pattern of mortality among size classes was not different to that of random chance (Appendix B). This indicates there may not have been selective mortality on body sizes among 'low treatment' juveniles, however the high level of mortality may have influenced the variation in body sizes, further reducing my ability to detect statistical differences between the two treatment groups.

The effects of treatment on juvenile competitive ability may have been confounded by the previous social experiences within growth treatment bins (Lehtonen et al., 2016). The outcomes of previous agonistic interactions between juveniles in the growth treatment bins may have influenced the outcomes of future interaction between individuals in the resource occupation trials, even if the fish in the trails had never encountered each other previously (Hsu et al., 2006).

The substantial variation in aggression between individuals may have been a consequence of the short observation times I used to quantify individuals aggression (3 min. per focal individual). The high variation may have reduced my ability to detect differences in aggression among individuals of different rank, particularly when densities were low (note the wide error bars in Fig. 3.5). However, I note here that individual aggressive behaviour did not vary significantly after recording aggressive interactions for 3 minutes per day over 8 consecutive days. This indicates 3 minute observation times may have been sufficient to characterise individual aggressive behaviour in the common triplefin, and that the high level of variation in aggression between individuals may be due to other sources (e.g., genetics [Van Oers et al., 2005] or social experience [Hsu et al., 2006]).

Lastly, I acknowledge the scope of the study in chapter 3 is limited to one cohort of fish, and does not account for variation between cohorts settling in different seasons, years or geographic areas. A wider study that includes temporal and spatial 
variation, with larger sample sizes, would be more appropriate to make more robust generalisations about the patterns identified in this study

\subsection{Conclusion}

In summary, populations are comprised of mixtures of individuals that vary in their life histories with corresponding consequences for individual phenotypes, behaviour and future success. This thesis contributes to a growing body of knowledge identifying the determinants of success in systems featuring male parental care, and highlights the importance of individual life history characteristics on the success of individuals at multiple life stages. Identifying the determinants of reproductive success is yet to be achieved in many other systems. Future research should account for variation in individual life histories, in relation to both maternal effects and environmental conditions during development. 


\section{Bibliography}

Ah-King, M., Kvarnemo, C. and Tullberg, B. S. (2005), 'The influence of territoriality and mating system on the evolution of male care: a phylogenetic study on fish', Journal of Evolutionary Biology 18(2), 371-382.

Álvarez, D. and Metcalfe, N. B. (2007), 'The tradeoff between catch-up growth and escape speed: variation between habitats in the cost of compensation', Oikos 116(7), 1144-1151.

Ammann, A. J. (2004), 'Smurfs: standard monitoring units for the recruitment of temperate reef fishes', Journal of Experimental Marine Biology and Ecology 299(2), 135154.

Amorim, M. C. P., da Ponte, A. N., Caiano, M., Pedroso, S. S., Pereira, R. and Fonseca, P. J. (2013), 'Mate preference in the painted goby: the influence of visual and acoustic courtship signals', Journal of Experimental Biology 216(21), 3996-4004.

Anderson, J. T. (1988), 'A review of size dependent survival during pre-recruit stages of fishes in relation to recruitment', Journal of Northwest Atlantic Fishery Science 8, 55-66.

Andersson, M. B. (1994), Sexual selection, Princeton University Press.

Andrén, M. N. and Kvarnemo, C. (2014), 'Filial cannibalism in a nest-guarding fish: females prefer to spawn in nests with few eggs over many', Behavioral Ecology and Sociobiology 68(10), 1565-1576.

Ang, T. Z. and Manica, A. (2010a), 'Aggression, segregation and stability in a dominance hierarchy', Proceedings of the Royal Society of London B: Biological Sciences p. rspb20091839.

Ang, T. Z. and Manica, A. (2010b), 'Unavoidable limits on group size in a body size-based linear hierarchy', Behavioral Ecology 21(4), 819-825.

Angilletta, M. J., Steury, T. D. and Sears, M. W. (2004), 'Temperature, growth rate, and body size in ectotherms: fitting pieces of a life-history puzzle', Integrative and Comparative Biology 44(6), 498-509.

Auer, S. K., Arendt, J. D., Chandramouli, R. and Reznick, D. N. (2010), 'Juvenile compensatory growth has negative consequences for reproduction in trinidadian guppies (poecilia reticulata)', Ecology Letters 13(8), 998-1007. 
Bailey, K. (1989), 'Predation on eggs and larvae of marine fishes and the recruitment problem', Adv. Mar. Biol. 25, 1-83.

Baltz, D. M., Fleeger, J. W., Rakocinski, C. F. and McCall, J. N. (1998), 'Food, density, and microhabitat: factors affecting growth and recruitment potential of juvenile saltmarsh fishes', Environmental Biology of Fishes 53(1), 89-103.

Barton, K. (2015), ‘Package 'mumin', Version 1, 18.

Bercovitch, F. B. (1991), 'Social stratification, social strategies, and reproductive success in primates', Ethology and Sociobiology 12(4), 315 - 333.

Bergenius, M. A., McCormick, M. I., Meekan, M. G. and Robertson, D. R. (2005), 'Environmental influences on larval duration, growth and magnitude of settlement of a coral reef fish', Marine Biology 147(2), 291-300.

Bertram, S. M. and Rook, V. (2012), 'Relationship between condition, aggression, signaling, courtship, and egg laying in the field cricket, gryllus assimilis', Ethology 118(4), 360-372.

Biro, P. A., Abrahams, M. V., Post, J. R. and Parkinson, E. A. (2004), ‘Predators select against high growth rates and risk-taking behaviour in domestic trout populations', Proceedings of the Royal Society of London B: Biological Sciences 271(1554), 22332237.

Bisazza, A., Marconato, A. and Marin, G. (1989), 'Male competition and female choice in padogobius martensi (pisces, gobiidae)', Animal Behaviour 38(3), 406 413.

Blob, R. W., Bridges, W. C., Ptacek, M. B., Maie, T., Cediel, R. A., Bertolas, M. M., Julius, M. L. and Schoenfuss, H. L. (2008), 'Morphological selection in an extreme flow environment: body shape and waterfall-climbing success in the hawaiian stream fish sicyopterus stimpsoni', Integrative and Comparative Biology 48(6), 734749.

Blumer, L. S. (1979), 'Male parental care in the bony fishes', The Quarterly Review of Biology 54(2), 149-161.

Booth, D. J. and Beretta, G. A. (2004), 'Influence of recruit condition on food competition and predation risk in a coral reef fish', Oecologia 140(2), 289-294. 
Brett, J., Shelbourn, J. E. and Shoop, C. T. (1969), 'Growth rate and body composition of fingerling sockeye salmon, oncorhynchus nerka, in relation to temperature and ration size', Journal of the Fisheries Board of Canada 26(9), 2363-2394.

Brown, J. H. and Maurer, B. A. (1986), 'Body size, ecological dominance and cope's rule', Nature 324(6094), 248-250.

Bshary, R. and Lamprecht, J. (1994), 'Reduction of aggression among domestic hens (gallus domesticus) in the presence of a dominant third party', Behaviour 128(3), 311-324.

Burnham, K. P. and Anderson, D. R. (2002), 'Model selection and multimodel inference: a practical information-theoretical approach'.

Buston, P. M. and Elith, J. (2011), 'Determinants of reproductive success in dominant pairs of clownfish: a boosted regression tree analysis', Journal of Animal Ecology 80(3), 528-538.

Candolin, U. (1999), 'The relationship between signal quality and physical condition: is sexual signalling honest in the three-spined stickleback?', Animal Behaviour 58(6), 1261-1267.

Candolin, U. (2000), 'Male-male competition ensures honest signaling of male parental ability in the three-spined stickleback (gasterosteus aculeatus)', Behavioral Ecology and Sociobiology 49(1), 57-61.

Candolin, U. and Voigt, H.-R. (2001), 'Correlation between male size and territory quality: consequence of male competition or predation susceptibility?', Oikos 95(2), 225-230.

Candolin, U. and Voigt, H.-R. (2003), 'Size-dependent selection on arrival times in sticklebacks: why small males arrive first', Evolution 57(4), 862-871.

Cargnelli, L. M. and Gross, M. R. (1996), 'The temporal dimension in fish recruitment: birth date, body size, and size-dependent survival in a sunfish (bluegill: Lepomis macrochirus)', Canadian Journal of Fisheries and Aquatic Sciences 53(2), 360367.

Chastel, O., Weimerskirch, H. and Jouventin, P. (1995), 'Influence of body condition on reproductive decision and reproductive success in the blue petrel', The Auk pp. 964-972. 
Clements, K. (2003), 'Triplefins', The living reef. The ecology of New ZealandâĂŹs rocky reefs. Craig Potton Publishing, Nelson pp. 160-167.

Clutton-Brock, T. (1988), Reproductive success: studies of individual variation in contrasting breeding systems, University of Chicago Press.

Clutton-Brock, T. H. (1991), The evolution of parental care, Princeton University Press.

Cockburn, A. (2006), 'Prevalence of different modes of parental care in birds', Proceedings of the Royal Society of London B: Biological Sciences 273(1592), 1375-1383.

Cole, K. S. (1982), 'Male reproductive behaviour and spawning success in a temperate zone goby, coryphopterus nicholsi', Canadian Journal of Zoology 60(10), 2309-2316.

Connell, S. and Jones, G. (1991), 'The influence of habitat complexity on postrecruitment processes in a temperate reef fish population', Journal of experimental marine biology and ecology 151(2), 271-294.

Côte, I. and Hunte, W. (1989), 'Male and female mate choice in the redlip blenny: why bigger is better', Animal Behaviour 38(1), 78-88.

Cutts, C., Brembs, B., Metcalfe, N. and Taylor, A. (1999), 'Prior residence, territory quality and life-history strategies in juvenile atlantic salmon (salmo salar 1.)', Journal of Fish Biology 55(4), 784-794.

Dickerson, B., Brinck, K., Willson, M., Bentzen, P. and Quinn, T. (2005), 'Relative importance of salmon body size and arrival time at breeding grounds to reproductive success', Ecology 86(2), 347-352.

Drews, C. (1993), 'The concept and definition of dominance in animal behaviour', Behaviour 125(3), 283-313.

Dzyuba, B., Van Look, K. J. W., Cliffe, A., Koldewey, H. J. and Holt, W. V. (2006), 'Effect of parental age and associated size on fecundity, growth and survival in the yellow seahorse hippocampus kuda', Journal of Experimental Biology 209(16), 30553061.

Enquist, M. and Leimar, O. (1987), 'Evolution of fighting behaviour: the effect of variation in resource value', Journal of theoretical Biology 127(2), 187-205.

Fagundes, T., Simões, M. G., Saraiva, J. L., Ros, A. F., Gonçalves, D. and Oliveira, R. F. (2015), 'Birth date predicts alternative life-history pathways in a fish with sequential reproductive tactics', Functional Ecology 29(12), 1533-1542. 
Feary, D. A. and Clements, K. D. (2006), 'Habitat use by triplefin species (tripterygiidae) on rocky reefs in new zealand.', Journal of Fish Biology 69(4), 1031 - 1046.

FitzGerald, G. J. (1992), 'Filial cannibalism in fishes: Why do parents eat their offspring?', Trends in Ecology \& Evolution 7(1), 7 - 10.

Forsgren, E. (1997), 'Female sand gobies prefer good fathers over dominant males', Proceedings of the Royal Society of London B: Biological Sciences 264(1386), 1283-1286.

Forsgren, E., Karlsson, A. and Kvarnemo, C. (1996), 'Female sand gobies gain direct benefits by choosing males with eggs in their nests', Behavioral Ecology and Sociobiology 39(2), 91-96.

Francis, M. (2001), Coastal fishes of New Zealand: an identification guide, Raupo.

Friedland, K. D., Hansen, L. P., Dunkley, D. A. and MacLean, J. C. (2000), 'Linkage between ocean climate, post-smolt growth, and survival of atlantic salmon (salmo salar 1.) in the north sea area', ICES Journal of Marine Science: Journal du Conseil 57(2), 419-429.

Fuxjager, M. J., Forbes-Lorman, R. M., Coss, D. J., Auger, C. J., Auger, A. P. and Marler, C. A. (2010), 'Winning territorial disputes selectively enhances androgen sensitivity in neural pathways related to motivation and social aggression', Proceedings of the National Academy of Sciences 107(27), 12393-12398.

G. A. Lozano, S. Perreault, R. E. L. (1996), 'Age, arrival date and reproductive success of male american redstarts setophaga ruticilla', Journal of Avian Biology 27(2), 164170.

Gagliano, M. and McCormick, M. I. (2007), 'Compensating in the wild: is flexible growth the key to early juvenile survival?', Oikos 116(1), 111-120.

Gagliano, M., McCormick, M. I. and Meekan, M. G. (2007), 'Survival against the odds: ontogenetic changes in selective pressure mediate growth-mortality tradeoffs in a marine fish', Proceedings of the Royal Society of London B: Biological Sciences 274(1618), 1575-1582.

Geange, S. W. and Stier, A. C. (2010), 'Priority effects and habitat complexity affect the strength of competition', Oecologia 163(1), 111-118.

Gomagano, D. and Kohda, M. (2008), Partial filial cannibalism enhances initial body condition and size in paternal care fish with strong male-male competition, in 'Annales Zoologici Fennici', Vol. 45, BioOne, pp. 55-65. 
Gross, M. R. and Sargent, R. C. (1985), 'The evolution of male and female parental care in fishes', American Zoologist 25(3), 807-822.

Habrun, C. A. and Sancho, G. (2012), 'Spawning ascent durations of pelagic spawning reef fishes', Curr Zool 58, 95-102.

Handford, C. (1979), 'The habitat, population dynamics and social organisation of two tripterygiid fishes', MSc Thesis. University of Auckland. .

Hanson, K. and Cooke, S. J. (2009), 'Why does size matter? a test of the benefits of female mate choice in a teleost fish based on morphological and physiological indicators of male quality', Physiological and Biochemical Zoology 82(6), 617-624. PMID: 19769537.

Harwood, A., Griffiths, S. W., Metcalfe, N. and Armstrong, J. (2003), 'The relative influence of prior residency and dominance on the early feeding behaviour of juvenile atlantic salmon', Animal Behaviour 65(6), 1141-1149.

Hawn, A. T., Martin, G. B., Sandin, S. A. and Hare, J. A. (2005), 'Early juvenile mortality in the coral reef fish chromis cyanea (pomacentridae): the growth-mortality hypothesis revisited', Bulletin of Marine Science 77(2), 309-318.

Hodge, S. J., Manica, A., Flower, T. P. and Clutton-Brock, T. H. (2008), 'Determinants of reproductive success in dominant female meerkats', Journal of Animal Ecology 77(1), 92-102.

Houde, E. D. (1989), 'Comparative growth, mortality, and energetics of marine fish larvae: temperature and implied latitudinal effects.', Fishery Bulletin 87(3), 471-495.

Hsu, Y., Earley, R. L. and Wolf, L. L. (2006), 'Modulation of aggressive behaviour by fighting experience: mechanisms and contest outcomes', Biological Reviews 81(1), 33-74.

Hutchings, J. A., Bishop, T. D. and McGregor-Shaw, C. R. (1999), 'Spawning behaviour of atlantic cod, gadus morhua: evidence of mate competition and mate choice in a broadcast spawner', Canadian Journal of Fisheries and Aquatic Sciences 56(1), 97-104.

Jacob, A., Evanno, G., Renai, E., Sermier, R. and Wedekind, C. (2009), 'Male body size and breeding tubercles are both linked to intrasexual dominance and reproductive success in the minnow', Animal Behaviour 77(4), 823 - 829. 
Jarvi, T. (1990), 'The effects of male dominance, secondary sexual characteristics and female mate choice on the mating success of male atlantic salmon salmo salar', Ethology 84(2), 123-132.

Jennings, M. J. and Philipp, D. P. (1992), 'Reproductive investment and somatic growth rates in longear sunfish', Environmental Biology of Fishes 35(3), 257-271.

Johnson, D. W. (2008), 'Combined effects of condition and density on post-settlement survival and growth of a marine fish', Oecologia 155(1), 43-52.

Johnsson, J. I. and Bohlin, T. (2006), 'The cost of catching up: increased winter mortality following structural growth compensation in the wild', Proceedings of the Royal Society of London B: Biological Sciences 273(1591), 1281-1286.

Johnsson, J., Nöbbelin, F. and Bohlin, T. (1999), 'Territorial competition among wild brown trout fry: effects of ownership and body size', Journal of Fish Biology 54(2), 469-472.

Karban, R. (1982), 'Increased reproductive success at high densities and predator satiation for periodical cicadas', Ecology pp. 321-328.

Kasumovic, M. M., Brooks, R. C. and Andrade, M. C. B. (2009), 'Body condition but not dietary restriction prolongs lifespan in a semelparous capital breeder', Biology Letters 5(5), 636-638.

Khan, J. and Herbert, N. (2012), 'The behavioural thermal preference of the common triplefin (forsterygion lapillum) tracks aerobic scope optima at the upper thermal limit of its distribution', Journal of Thermal Biology 37(2), 118-124.

Kiltie, R. A. (1982), 'Intraspecific variation in the mammalian gestation period', Journal of Mammalogy 63(4), 646-652.

Knapp, R. A. and Kovach, J. T. (1991), 'Courtship as an honest indicator of male parental quality in the bicolor damselfish, stegastes partitus', Behavioral Ecology 2(4), 295-300.

Lee, G., Grant, J. W. and Comolli, P. (2011), 'Dominant convict cichlids (amatitlania nigrofasciata) grow faster than subordinates when fed an equal ration', Behaviour 148(8), 877-887.

Lee, W.-S., Metcalfe, N. B., Réale, D. and Peres-Neto, P. R. (2014), 'Early growth trajectories affect sexual responsiveness', Proceedings of the Royal Society of London B: Biological Sciences 281(1777), 20132899. 
Lee, W.-S., Monaghan, P. and Metcalfe, N. B. (2012), 'The pattern of early growth trajectories affects adult breeding performance', Ecology 93(4), 902-912.

Lehtonen, T. K. and Lindstrom, K. (2009), 'Females decide whether size matters: plastic mate preferences tuned to the intensity of maleâĂŞmale competition', Behavioral Ecology 20(1), 195-199.

Lehtonen, T. K., Svensson, P. A. and Wong, B. B. (2016), 'The influence of recent social experience and physical environment on courtship and male aggression', BMC Evolutionary Biology 16(1), 1.

Levitan, D. R. (2005), 'The distribution of male and female reproductive success in a broadcast spawning marine invertebrate', Integrative and Comparative Biology 45(5), 848-855.

Lindholm, A., Gauthier, G. and Desrochers, A. (1994), 'Effects of hatch date and food supply on gosling growth in arctic-nesting greater snow geese', Condor pp. 898908.

Lindström, K. (1992), 'The effect of resource holding potential, nest size and information about resource quality on the outcome of intruder-owner conflicts in the sand goby', Behavioral Ecology and Sociobiology 30(1), 53-58.

Lindström, K. and Hellström, M. (1993), 'Male size and parental care in the sand goby, pomatoschistus minutus', Ethology ecology \& evolution 5(1), 97-106.

Lindstrom, K. and Sargent, C. R. (1997), 'Food access, brood size and filial cannibalism in the fantail darter, etheostoma flabellare', Behavioral Ecology and Sociobiology 40(2), 107-110.

López-Sepulcre, A. and Kokko, H. (2005), 'Territorial defense, territory size, and population regulation', The American Naturalist 166(3), 317-325.

MacKenzie, B. R. and Kiørboe, T. (2000), 'Larval fish feeding and turbulence: a case for the downside', Limnology and Oceanography 45(1), 1-10.

Mackereth, R. W., Noakes, D. L. G. and Ridgway, M. S. (1998), When do fishes become juveniles?, Springer Netherlands, Dordrecht, chapter Size-based variation in somatic energy reserves and parental expenditure by male smallmouth bass, $\mathrm{Mi}-$ cropterus dolomieu, pp. 263-275.

Madsen, T., Shine, R., Loman, J. and HÃČ Âěkansson, T. (1993), 'Determinants of mating success in male adders, vipera berus', Animal Behaviour 45(3), 491 - 499. 
Magnhagen, C. and Kvarnemo, L. (1989), 'Big is better: the importance of size for reproductive success in male pomatoschistus minutus (pallas)(pisces, gobiidae)', Journal of Fish Biology 35(6), 755-763.

Maher, C. R. and Lott, D. F. (1995), 'Definitions of territoriality used in the study of variation in vertebrate spacing systems', Animal behaviour 49(6), 1581-1597.

Maller, A. P. and Thornhill, R. (1998), 'Male parental care, differential parental investment by females and sexual selection', Animal Behaviour 55(6), 1507 - 1515.

Marconato, A. and Bisazza, A. (1986), 'Males whose nests contain eggs are preferred by female cottus gobio 1.(pisces, cottidae)', Animal Behaviour 34(5), 1580-1582.

Masello, J. F. and Quillfeldt, P. (2003), 'Body size, body condition and ornamental feathers of burrowing parrots: variation between years and sexes, assortative mating and influences on breeding success.', Emu (103), 149-163.

Matthews, S. A. and Wong, M. Y. (2015), 'Temperature-dependent resolution of conflict over rank within a size-based dominance hierarchy', Behavioral Ecology 26(3), 947-958.

Mauck, R. A., Huntington, C. E. and Grubb, T. C. (2004), 'Age-specific reproductive success: Evidence for the selection hypothesis', Evolution 58(4), 880-885.

McDermott, C. J. and Shima, J. S. (2006), 'Ontogenetic shifts in microhabitat preference of the temperate reef fish forsterygion lapillum: implications for population limitation', Marine Ecology Progress Series 320, 259-266.

McElligott, A. G., Gammell, M. P., Harty, H. C., Paini, D. R., Murphy, D. T., Walsh, J. T. and Hayden, T. J. (2001), 'Sexual size dimorphism in fallow deer (dama dama): do larger, heavier males gain greater mating success?', Behavioral Ecology and Sociobiology 49(4), 266-272.

Meekan, M. G. and Fortier, L. (1996), 'Selection for fast growth during the larval life of atlantic cod gadus morhua on the scotian shelf', Marine Ecology Progress Series 137(1), 25-37.

Meekan, M., Vigliola, L., Hansen, A., Doherty, P., Halford, A., Carleton, J. et al. (2006), 'Bigger is better: size-selective mortality throughout the life history of a fast-growing clupeid, spratelloides gracilis', MARINE ECOLOGY-PROGRESS SERIES- 317, 237. 
Mensink, P., Geange, S. and Shima, J. (2014), 'Reproductive success of parasitized males in a marine reef fish.', Marine Biology 161(11), 2689 - 2696.

Mensink, P. J. (2014), 'Factors influencing the recruitment, growth and reproduction of a temperate reef fish, forsterygion lapillum', PhD Dissertation .

Mensink, P. J. and Shima, J. S. (2015), 'Home-range size in juveniles of the temperate reef fish, the common triplefin (forsterygion lapillum)', Marine and Freshwater Research .

Metcalfe, N. B. and Monaghan, P. (2001), 'Compensation for a bad start: grow now, pay later?', Trends in ecology E evolution 16(5), 254-260.

Metcalfe, N. B. and Monaghan, P. (2003), 'Growth versus lifespan: perspectives from evolutionary ecology', Experimental gerontology 38(9), 935-940.

Michael A. Farris, M. J. L. (1990), 'Functional interactions among traits that determine reproductive success in a native annual plant', Ecology 71(2), 548-557.

Monaghan, P. (2008), 'Early growth conditions, phenotypic development and environmental change', Philosophical Transactions of the Royal Society of London B: Biological Sciences 363(1497), 1635-1645.

Morales, M. B., Alonso, J., Martín, C., Martín, E. and Alonso, J. (2003), 'Male sexual display and attractiveness in the great bustard otis tarda: the role of body condition', Journal of Ethology 21(1), 51-56.

Morton, D. N. and Shima, J. S. (2013), 'Habitat configuration and availability influences the settlement of temperate reef fishes (tripterygiidae)', Journal of Experimental Marine Biology and Ecology 449, 215-220.

Mumby, P. J. and Wabnitz, C. C. (2002), 'Spatial patterns of aggression, territory size, and harem size in five sympatric caribbean parrotfish species', Environmental Biology of Fishes 63(3), 265-279.

Munday, P. L. (2001), 'Fitness consequences of habitat use and competition among coral-dwelling fishes', Oecologia 128(4), 585-593.

Neuheimer, A., Thresher, R., Lyle, J. and Semmens, J. (2011), 'Tolerance limit for fish growth exceeded by warming waters', Nature Climate Change 1(2), 110-113.

Nicieza, A. and Metcalfe, N. (1999), 'Costs of rapid growth: the risk of aggression is higher for fast-growing salmon', Functional Ecology 13(6), 793-800. 
Nielsen, J. L. (1992), 'Microhabitat-specific foraging behavior, diet, and growth of juvenile coho salmon', Transactions of the American Fisheries Society 121(5), 617-634.

Nowbahari, E., Feneron, R. and Malherbe, M.-C. (1999), 'Effect of body size on aggression in the ant, cataglyphis niger (hymenoptera; formicidae)', Aggressive Behavior 25(5), 369-379.

O'Connor, C. M., Reddon, A. R., Ligocki, I. Y., Hellmann, J. K., Garvy, K. A., MarshRollo, S. E., Hamilton, I. M. and Balshine, S. (2015), 'Motivation but not body size influences territorial contest dynamics in a wild cichlid fish', Animal Behaviour 107, 19-29.

Oliveira, R. F., Miranda, J., Carvalho, N., Gonçalves, E. J., Grober, M. S. and Santos, R. S. (2000), 'Male mating success in the azorean rock-pool blenny: the effects of body size, male behaviour and nest characteristics', Journal of fish biology 57(6), 1416-1428.

Olsson, M. and Shine, R. (1996), 'Does reproductive success increase with age or with size in species with indeterminate growth? a case study using sand lizards (lacerta agilis)', Oecologia 105(2), 175-178.

O'Neill, K. M. (1983), 'Territoriality, body size, and spacing in males of the beewolf philanthus basilaris (hymenoptera; sphecidae)', Behaviour 86(3), 295-321.

Ostfeld, R. S. (1990), 'The ecology of territoriality in small mammals', Trends in Ecology E Evolution 5(12), 411-415.

Parker, G. and Sutherland, W. (1986), 'Ideal free distributions when individuals differ in competitive ability: phenotype-limited ideal free models', Animal Behaviour 34(4), 1222-1242.

Pauly, D. (1980), 'On the interrelationships between natural mortality, growth parameters, and mean environmental temperature in 175 fish stocks', Journal du Conseil 39(2), 175-192.

Pepin, P. (1992), 'Significance of body size to the interaction between a larval fish (mallotus villosus) and a vertebrate predator (gasterosteus aculeatus)', Mar. Ecol. Prog. Ser. 81, 1-12.

Perez, K. O. and Munch, S. B. (2010), 'Extreme selection on size in the early lives of fish', Evolution 64(8), 2450-2457. 
Perrone, M. (1978), 'Mate size and breeding success in a monogamous cichlid fish', Environmental Biology of Fishes 3(2), 193-201.

Petty, J. T. and Grossman, G. D. (2007), 'Size-dependent territoriality of mottled sculpin in a southern appalachian stream', Transactions of the American Fisheries Society 136(6), 1750-1761.

Porter, B. A., Fiumera, A. C. and Avise, J. C. (2002), ‘Egg mimicry and allopaternal care: two mate-attracting tactics by which nesting striped darter (etheostoma virgatum) males enhance reproductive success', Behavioral Ecology and Sociobiology 51(4), 350-359.

Reid, J. M., Arcese, P., Cassidy, A. L., Hiebert, S. M., Smith, J. N., Stoddard, P. K., Marr, A. B. and Keller, L. F. (2004), 'Song repertoire size predicts initial mating success in male song sparrows, melospiza melodia', Animal Behaviour 68(5), 10551063.

Ridley, M. and Rechten, C. (1981), 'Female sticklebacks prefer to spawn with males whose nests contain eggs', Behaviour 76(1), 152-161.

Ripley, B., Venables, B., Bates, D. M., Hornik, K., Gebhardt, A., Firth, D. and Ripley, M. B. (2015), 'Package âĂŸmassâĂŹ'.

Ros, A. F., Becker, K. and Oliveira, R. F. (2006), 'Aggressive behaviour and energy metabolism in a cichlid fish, oreochromis mossambicus', Physiology $\mathcal{E}$ behavior 89(2), 164-170.

Rowe, D. and Thorpe, J. (1990), 'Suppression of maturation in male atlantic salmon (salmo salar 1.) parr by reduction in feeding and growth during spring months', Aquaculture 86(2Ã cấĆňâĂIJ3), 291 - 313.

Rowland, W. J. (1989), 'The effects of body size, aggression and nuptial coloration on competition for territories in male threespine sticklebacks, gasterosteus aculeatus', Animal Behaviour 37, 282-289.

Ruby, D. E. (1984), 'Male breeding success and differential access to females in anolis carolinensis', Herpetologica 40(3), 272-280.

Schmidt-Roach, S., Miller, K. J., Woolsey, E., Gerlach, G. and Baird, A. H. (2012), 'Broadcast spawning by pocillopora species on the great barrier reef', PloS one 7(12), e50847. 
Schuett, G. W. (1997), 'Body size and agonistic experience affect dominance and mating success in male copperheads', Animal Behaviour 54(1), 213-224.

Shima, J. S. and Findlay, A. M. (2002), 'Pelagic larval growth rate impacts benthic settlement and survival of a temperate reef fish', Marine Ecology Progress Series 235, 303-309.

Shima, J. S., McNaughtan, D., Geange, S. W. and Wilkinson, S. (2012), 'Ontogenetic variation in site fidelity and homing behaviour of a temperate reef fish', Journal of Experimental Marine Biology and Ecology 416, 162-167.

Shima, J. S., Noonburg, E. G. and Swearer, S. E. (2015), 'Consequences of variable larval dispersal pathways and resulting phenotypic mixtures to the dynamics of marine metapopulations', Biology letters 11(2), 20140778.

Shima, J. S. and Swearer, S. E. (2009), 'Larval quality is shaped by matrix effects: implications for connectivity in a marine metapopulation', Ecology 90(5), 12551267.

Skoglund, H., Einum, S. and Robertsen, G. (2011), 'Competitive interactions shape offspring performance in relation to seasonal timing of emergence in atlantic salmon', Journal of Animal Ecology 80(2), 365-374.

Smith, A. C. and Shima, J. S. (2011), 'Variation in the effects of larval history on juvenile performance of a temperate reef fish', Austral Ecology 36(7), 830-838.

Smith, J. M. (1979), 'Game theory and the evolution of behaviour', Proceedings of the Royal Society of London B: Biological Sciences 205(1161), 475-488.

Smith, R. L. (1980), 'Evolution of exclusive postcopulatory paternal care in the insects', The Florida Entomologist 63(1), 65-78.

Sponaugle, S., Grorud-Colvert, K. and Pinkard, D. (2006), 'Temperature-mediated variation in early life history traits and recruitment success of the coral reef fish thalassoma bifasciatum in the florida keys', Marine Ecology Progress Series 308, 1-15.

Stamps, J. (1983), 'Territoriality and the defence of predator-refuges in juvenile lizards', Animal Behaviour 31(3), 857-870.

Stamps, J. A. (2007), 'Growth-mortality tradeoffs and 'personality traits' in animals', Ecology Letters 10(5), 355-363. 
Thompson, S. (1986), 'Male spawning success and female choice in the mottled triplefin, forsterygion varium (pisces: Tripterygiidae)', Animal Behaviour 34(2), 580589.

Thorley, J. B. and Lord, A. M. (2015), 'Laying date is a plastic and repeatable trait in a population of blue tits cyanistes caeruleus', Ardea 103(1), 69-78.

Tokarz, R. R. (1985), 'Body size as a factor determining dominance in staged agonistic encounters between male brown anoles (anolis sagrei)', Animal Behaviour 33(3), 746-753.

Trivers, R. (1972), Parental investment and sexual selection, Vol. 136, Biological Laboratories, Harvard University.

Tupper, M. and Boutilier, R. (1995), 'Effects of habitat on settlement, growth, and postsettlement survival of atlantic cod (gadus morhua)', Canadian Journal of Fisheries and Aquatic Sciences 52(9), 1834-1841.

Uller, T. and Olsson, M. (2010), 'Offspring size and timing of hatching determine survival and reproductive output in a lizard', Oecologia 162(3), 663-671.

Uusi-Heikkilä, S., Kuparinen, A., Wolter, C., Meinelt, T. and Arlinghaus, R. (2011), 'Paternal body size affects reproductive success in laboratory-held zebrafish (danio rerio)', Environmental Biology of Fishes 93(4), 461-474.

Van Oers, K., De Jong, G., Van Noordwijk, A. J., Kempenaers, B. and Drent, P. J. (2005), 'Contribution of genetics to the study of animal personalities: a review of case studies', Behaviour 142(9-10), 1185-1206.

Vance, R. R. (1973), 'On reproductive strategies in marine benthic invertebrates', American Naturalist pp. 339-352.

Verhulst, S. and Nilsson, J.- $\AA$. (2008), 'The timing of birds' breeding seasons: a review of experiments that manipulated timing of breeding', Philosophical Transactions of the Royal Society of London B: Biological Sciences 363(1490), 399-410.

Vinyoles, D., Sostoa, A. et al. (1999), 'Egg cannibalism in river blennies: the role of natural prey availability', Journal of Fish Biology 55(6), 1223-1232.

Walling, C. A., Royle, N. J., Metcalfe, N. B. and Lindström, J. (2007), ‘Early nutritional conditions, growth trajectories and mate choice: does compensatory growth lead to a reduction in adult sexual attractiveness?', Behavioral Ecology and Sociobiology 61(7), 1007-1014. 
Warwick, N. W. and Brock, M. A. (2003), 'Plant reproduction in temporary wetlands: the effects of seasonal timing, depth, and duration of flooding', Aquatic Botany 77(2), $153-167$.

Wauters, L. and Dhondt, A. A. (1989), 'Body weight, longevity and reproductive success in red squirrels (sciurus vulgaris)', The Journal of Animal Ecology pp. 637651.

Wehrberger, F. and Herler, J. (2014), 'Microhabitat characteristics influence shape and size of coral-associated fishes', Marine Ecology Progress Series 500, 203.

Wellenreuther, M., Barrett, P. T. and Clements, K. D. (2007), 'Ecological diversification in habitat use by subtidal triplefin fishes (tripterygiidae)', Marine Ecology Progress Series 330, 235-246.

Wellenreuther, M. and Clements, K. (2007a), 'Reproductive isolation in temperate reef fishes.', Marine Biology 152(3), 619 - 630.

Wellenreuther, M. and Clements, K. D. (2007b), 'Reproductive isolation in temperate reef fishes', Marine Biology 152(3), 619-630.

Wenger, A. S., McCormick, M. I., Endo, G. G., McLeod, I. M., Kroon, F. J. and Jones, G. P. (2014), 'Suspended sediment prolongs larval development in a coral reef fish', Journal of Experimental Biology 217(7), 1122-1128.

Werner, E. E. and Gilliam, J. F. (1984), 'The ontogenetic niche and species interactions in size-structured populations', Annual review of ecology and systematics 15, 393-425.

Williams, G. C. (1992), Natural selection, Oxford University Press.

Willis, T. J. (2001), 'Visual census methods underestimate density and diversity of cryptic reef fishes', Journal of Fish Biology 59(5), 1408-1411.

Winter, C., Lehmann, S. and Diekmann, M. (2008), 'Determinants of reproductive success: a comparative study of five endangered river corridor plants in fragmented habitats', Biological Conservation 141(4), 1095-1104.

Wong, M. Y., Munday, P. L., Buston, P. M. and Jones, G. P. (2008), 'Fasting or feasting in a fish social hierarchy', Current Biology 18(9), R372-R373.

Woodroffe, R. and Vincent, A. (1994), 'Mother's little helpers: patterns of male care in mammals', Trends in Ecology \& Evolution 9(8), 294-297. 


\section{Appendix A: Chapter 3 supplimentary material}

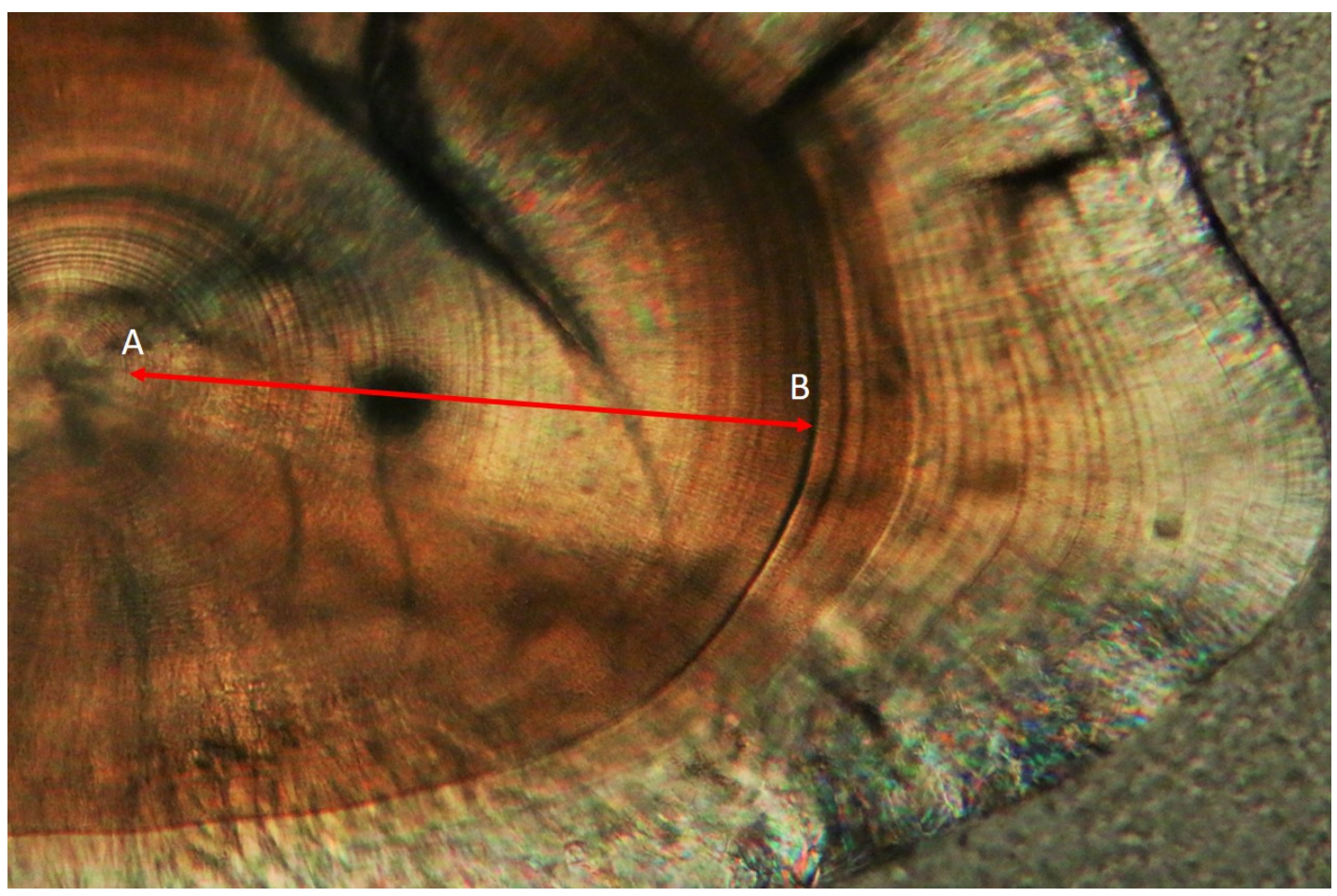

Figure 1: A sagittal otolith (200x magnification) extracted from a juvenile F. lapillum after being handground to expose daily growth increments. The red transect line is drawn from the 'hatch check' (A) to the 'settlement check' (B) across the postrostral axis, as defined by Shima and Swearer (2009). Photo credit: Ben Moginie 


\section{Appendix B: Patterns of growth treatment mortality in chapter 3}

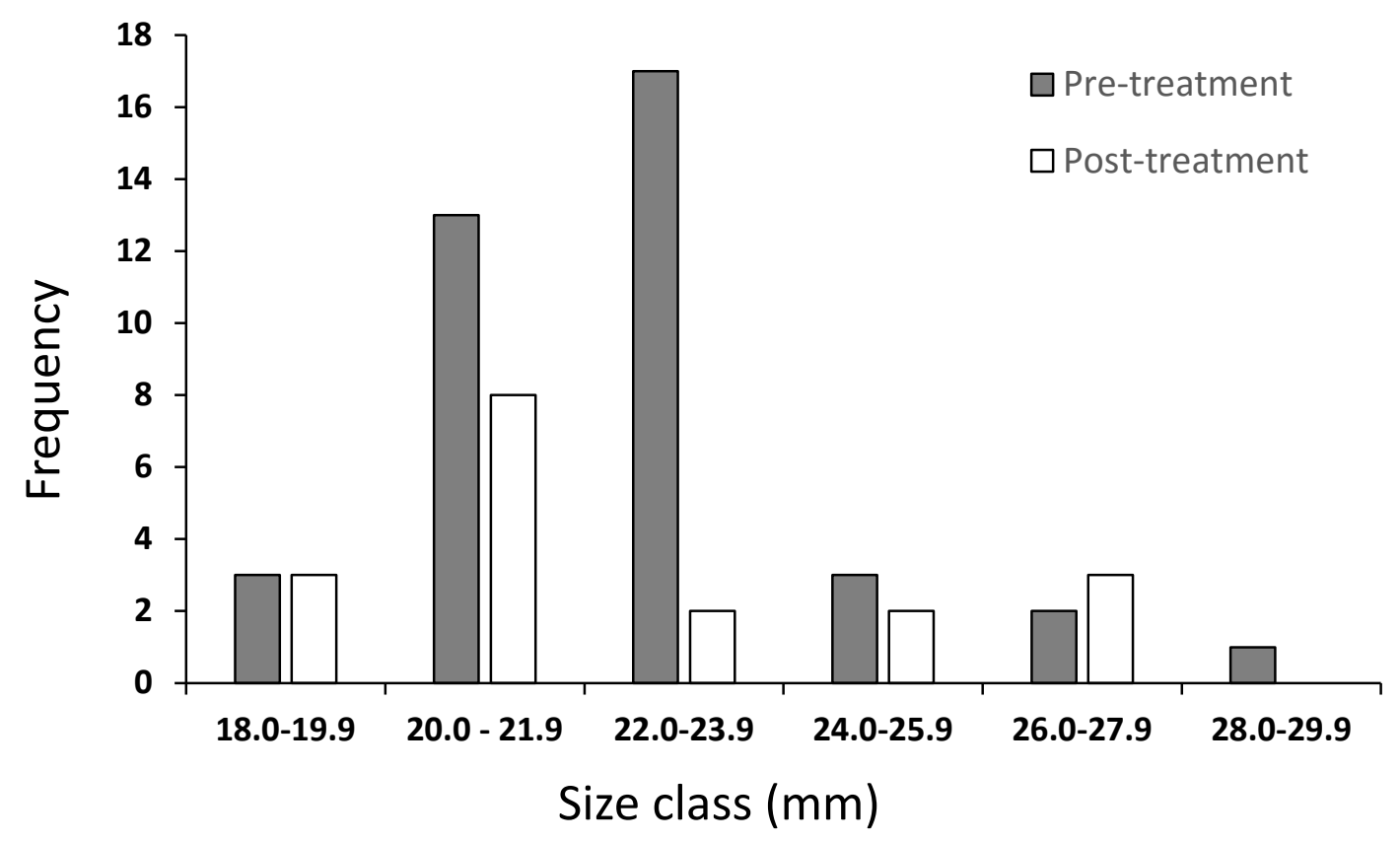

Figure 2: Frequency bar chart of size classess of juveniels exposed to the 'low' growth treatment. Classes are split into $1.9 \mathrm{~mm}$ groups based on standard length. Grey bars represent fish pre-treatment and white bars represent fish post-treatment

I performed a chi-square test on the grouped standard lengths of 'low treatment' juveniles based on scaled photographs taken before and after the application of the growth treatment. The results suggest the pattern of mortality among juveniles subject to the 'low treatment' was not different to that of random chance $\left(\mathrm{X}^{2}{ }_{4}: 3.238, \mathrm{P}\right.$ : 0.5188, Fig. 2). 